\title{
Measure Guideline: Guidance on Taped Insulating Sheathing Drainage Planes
}

A. Grin and J. Lstiburek Building Science Corporation

September 2014
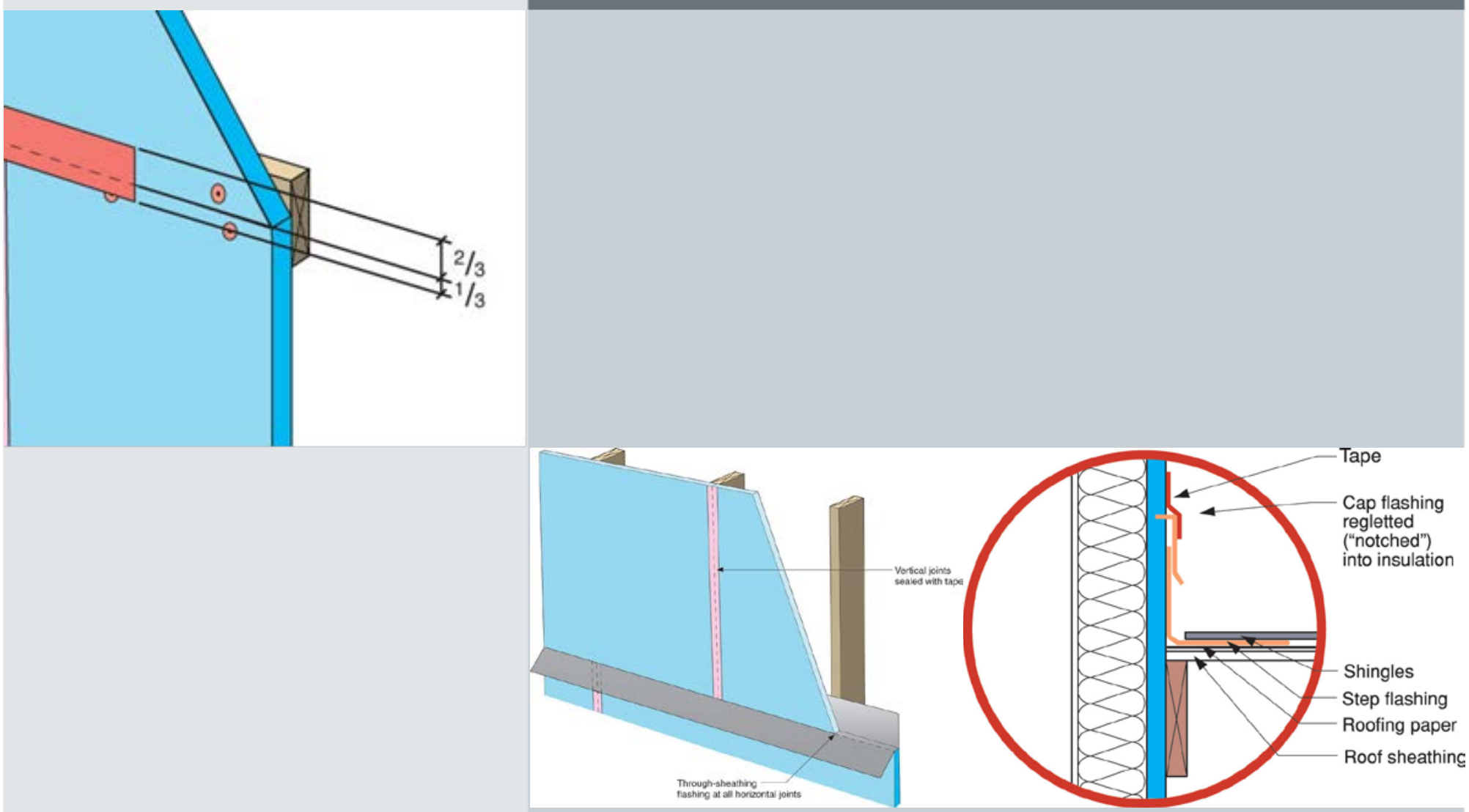


\section{NOTICE}

This report was prepared as an account of work sponsored by an agency of the United States government. Neither the United States government nor any agency thereof, nor any of their employees, subcontractors, or affiliated partners makes any warranty, express or implied, or assumes any legal liability or responsibility for the accuracy, completeness, or usefulness of any information, apparatus, product, or process disclosed, or represents that its use would not infringe privately owned rights. Reference herein to any specific commercial product, process, or service by trade name, trademark, manufacturer, or otherwise does not necessarily constitute or imply its endorsement, recommendation, or favoring by the United States government or any agency thereof. The views and opinions of authors expressed herein do not necessarily state or reflect those of the United States government or any agency thereof.

Available electronically at http://www.osti.gov/scitech

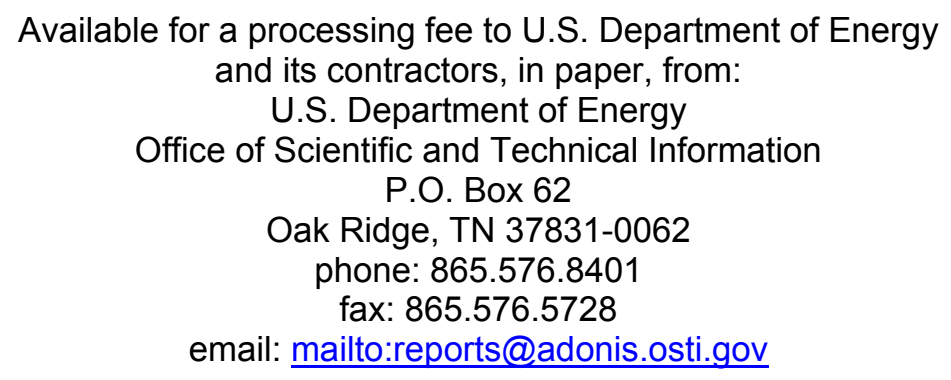

Available for sale to the public, in paper, from:

U.S. Department of Commerce

National Technical Information Service

5285 Port Royal Road

Springfield, VA 22161

phone: 800.553 .6847

fax: 703.605 .6900

email: orders@ntis.fedworld.gov

online ordering: http://www.ntis.gov/ordering.htm 


\title{
Measure Guideline: Guidance on Taped Insulating Sheathing Drainage Planes
}

\author{
Prepared for: \\ The National Renewable Energy Laboratory \\ On behalf of the U.S. Department of Energy's Building America Program \\ Office of Energy Efficiency and Renewable Energy \\ 15013 Denver West Parkway \\ Golden, CO 80401 \\ NREL Contract No. DE-AC36-08GO28308 \\ Prepared by: \\ Building Science Corporation \\ 30 Forest Street \\ Somerville, MA 02143 \\ NREL Technical Monitor: Stacey Rothgeb \\ Prepared under Subcontract No. KNDJ-1-40337-03
}

September 2014 
The work presented in this report does not represent performance of any product relative to regulated minimum efficiency requirements.

The laboratory and/or field sites used for this work are not certified rating test facilities. The conditions and methods under which products were characterized for this work differ from standard rating conditions, as described.

Because the methods and conditions differ, the reported results are not comparable to rated product performance and should only be used to estimate performance under the measured conditions. 


\section{Contents}

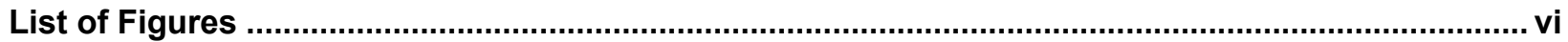

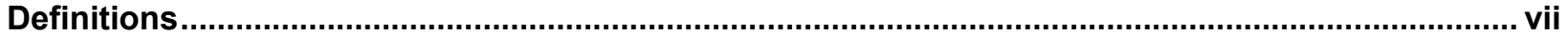

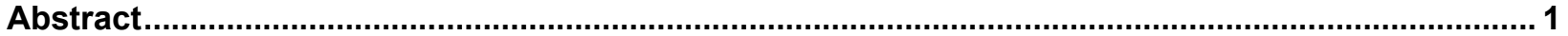

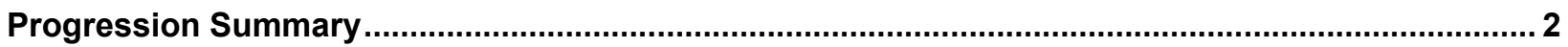

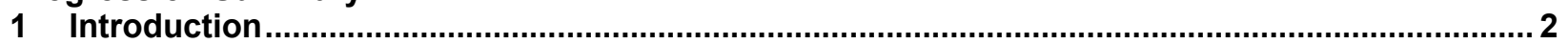

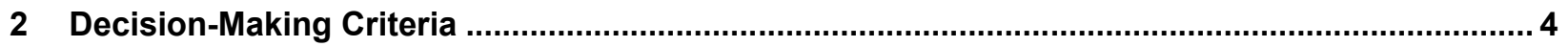

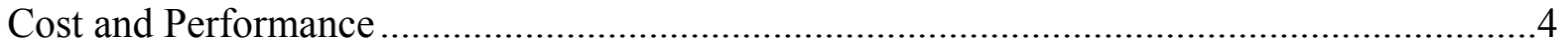

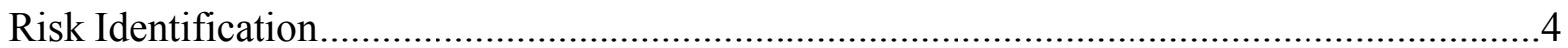

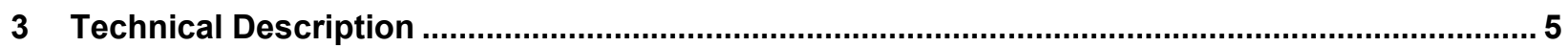

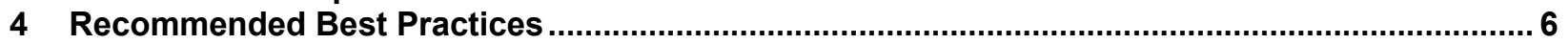

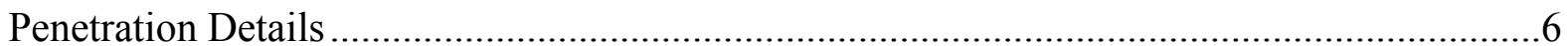

Insulating Sheathing Joint Requirements, Recommendations, and Tape Materials ...............10

5 Construction Sequencing Details for Recommendations........................................................ 14

GOOD_Basic Exterior Insulation Drainage Plane ......................................................... 14

BETTER - Improved Exterior Insulation Drainage Plane .............................................. 17

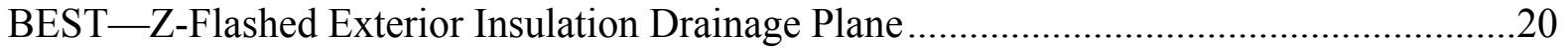

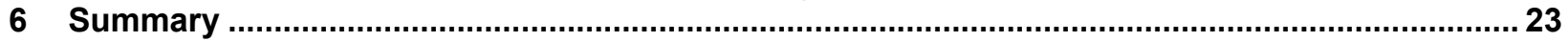

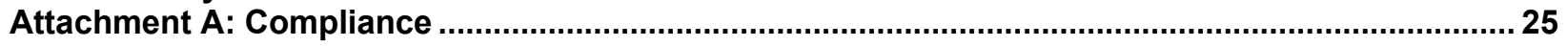

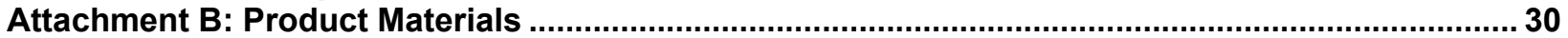

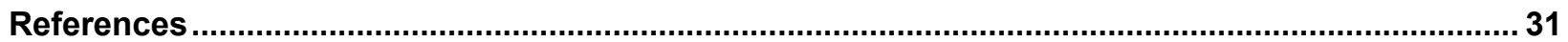

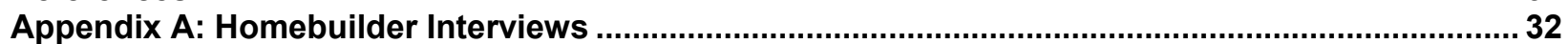

Appendix B: Future Research-Exposure Rack Recommendation Verification.............................. 33

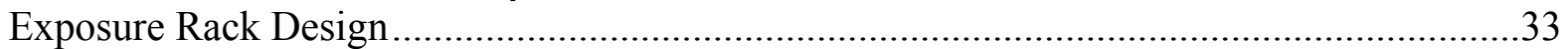

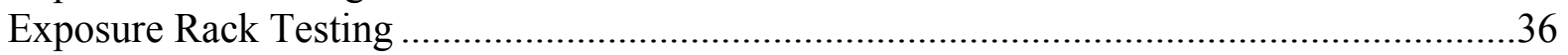




\section{List of Figures}

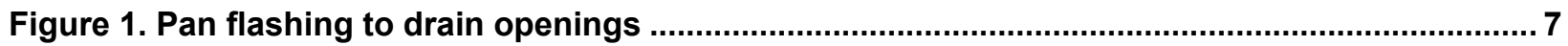

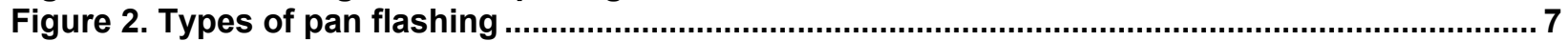

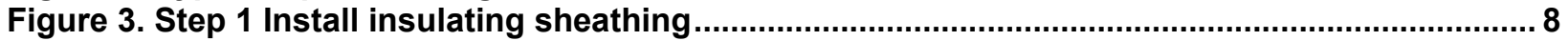

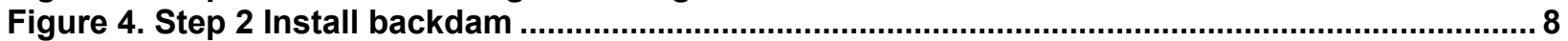

Figure 5. Step 3 Apply first piece of self-adhered sill flashing .................................................... 8

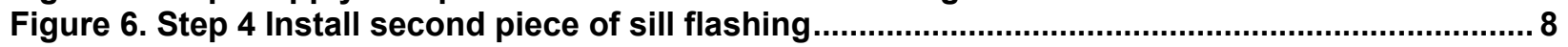

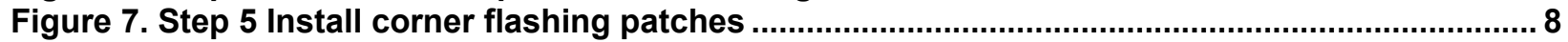

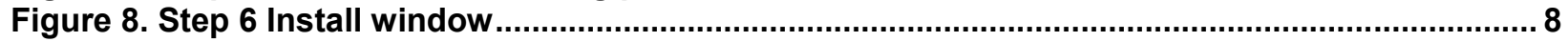

Figure 9. Step 7 Install self-adhered jamb flashing ….................................................................... 9

Figure 10. Step 8 Install self-adhered head flashing ....................................................................... 9

Figure 11. Step 9 Termination tape top edge of head flashing ......................................................... 9

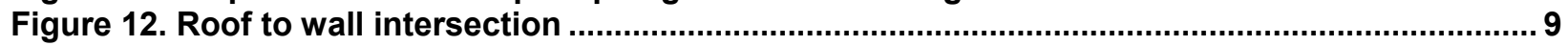

Figure 13. Example through drainage plane Z-flashing ................................................................. 12

Figure 14. Example termination tape offset high on butyl tape ...................................................... 12

Figure 15. Example wide tape intentionally offset high .............................................................. 13

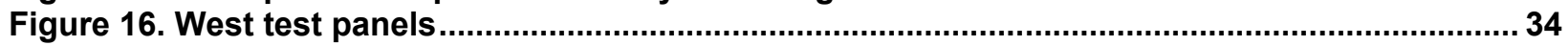

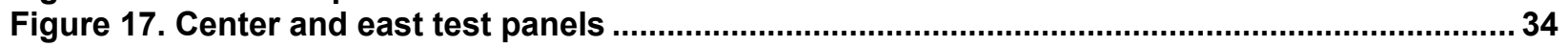

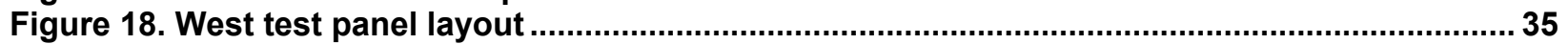

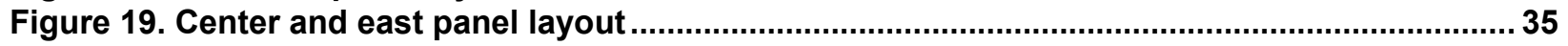

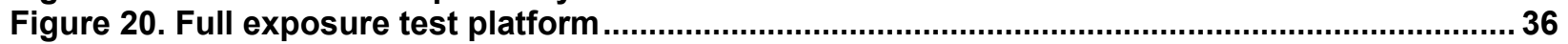

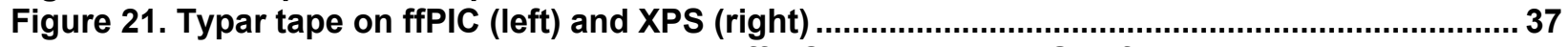

Figure 22. Typar tape with termination tape on ffPIC (right) and XPS (left)...................................... 37

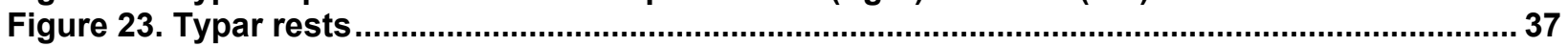

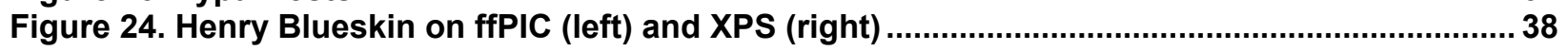

Figure 25. Henry Blueskin with termination tape on ffPIC (right) and XPS (left)............................... 38

Figure 26. Henry Blueskin tests ................................................................................................. 38

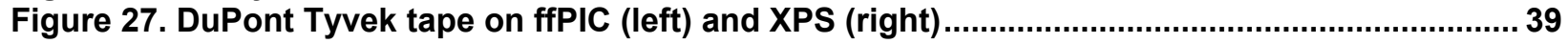

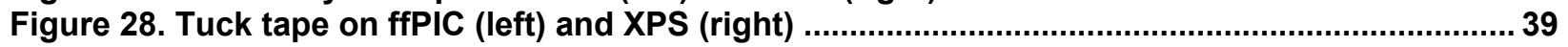

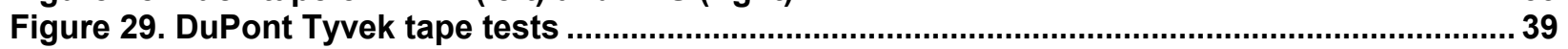

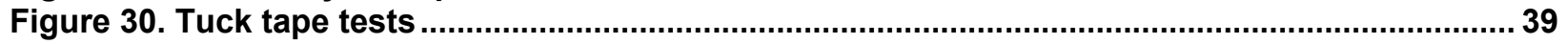

Figure 31. DuPont Straightflash tape on ffPIC (left) and XPS (right) ............................................ 40

Figure 32. DuPont Straightflash tape tests ........................................................................................ 40

Figure 33. Dow Weathermate butyl with termination tape on ffPIC (left) and XPS (right) ................. 41

Figure 34. Dow Weathermate butyl with termination tape tests .................................................... 41

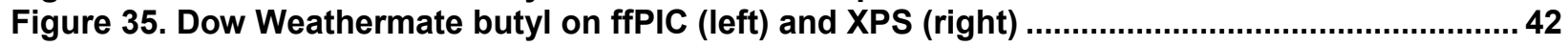

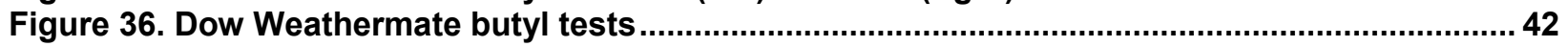

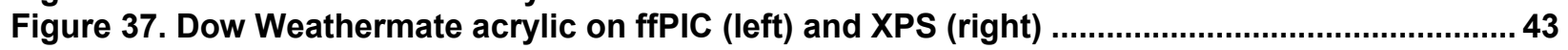

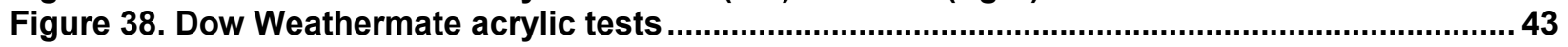

Figure 39. Dow Weathermate acrylic on ffPIC_large test...................................................... 44

Figure 40. Dow aluminum white foil on ffPIC-large test ........................................................... 44

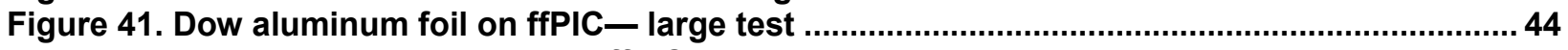

Figure 42. Dow Weathermate butyl on ffPIC -large test............................................................... 44

Figure 43. Dow Weathermate acrylic on XPS_large sample ............................................................ 45

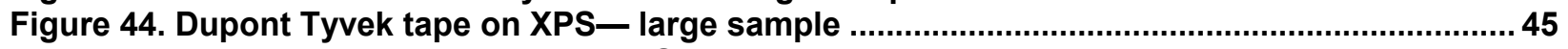

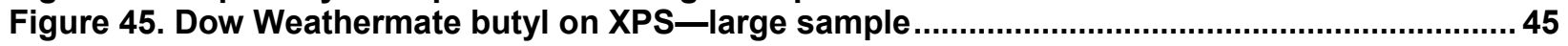

Figure 46. Dupont Straightflash on XPS - large sample ................................................................ 45

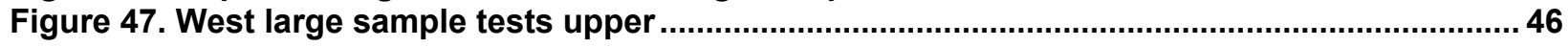

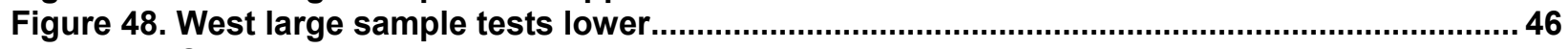

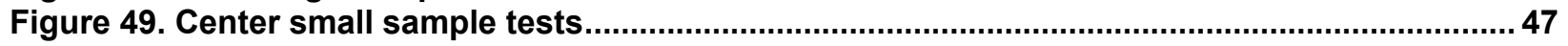

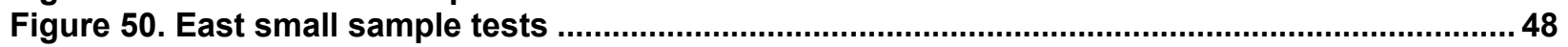




\section{Definitions}

ffPIC Foil Faced Polyisocyanurate

XPS Extruded Polystyrene 


\section{Abstract}

This guide provides information and recommendations to the following groups:

- Insulation contractors

- General contractors

- Builders

- Home remodelers

- Mechanical contractors

- Homeowners as a guide to the work that needs to be done.

The order of work completed during home construction and retrofit improvements is important. Health and safety issues must be addressed first and are more important than durability issues. And durability issues are more important than saving energy. Not all techniques can apply to all houses. Special conditions will require special action. Some builders or homeowners will wish to do more than the important but basic retrofit strategies outlined by this guide.

The following research was conducted by the Building Science Corporation Building America Research Team's “Energy Efficient Housing Research Partnerships” project for Task Order No. KNDJ-1-40337-03. Guidance on Taped Insulating Sheathing Drainage Planes is Subtask 7.2 under Task 7.0 - Evaluation of Advanced Retrofit Measures and Development of Retrofit Measure Guidelines. The goal of this research is to provide durable and long-term water management solutions using exterior insulating sheathing as part of the water management system. It is possible to tape or seal the joints in insulating sheathing to create a drainage plane and even an air control layer. There exists the material durability component of the tape as well as the system durability component being the taped insulating sheathing as the drainage plane.

The following are best practice and product recommendations from the interviewed contractors and homebuilders who collectively have a vast amount of experience. Three significant items were discussed with the group, which are required to make taped insulating sheathing a simple, long-term, and durable drainage plane:

1. Horizontal joints should be limited or eliminated wherever possible.

2. Where a horizontal joint exists use superior materials.

3. Frequent installation inspection and regular trade training are required to maintain proper installation.

Section 5 of this measure guideline contains the detailed construction procedure for the three recommended methods to effectively seal the joints in exterior insulating sheathing to create a simple, long-term, and durable drainage plane. 


\section{Progression Summary}

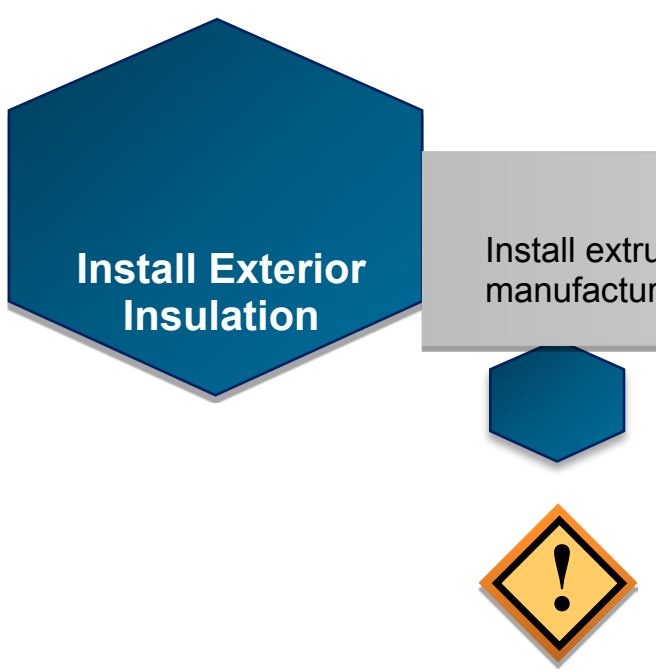

Do Not Proceed if:

- Surfaces are dusty or dirty

- Surfaces are wet or icy

- Large gaps in exterior insulation exist

- Exterior temperature is below $15^{\circ} \mathrm{F}$

- Insulating sheathing is not XPS or ffPIC

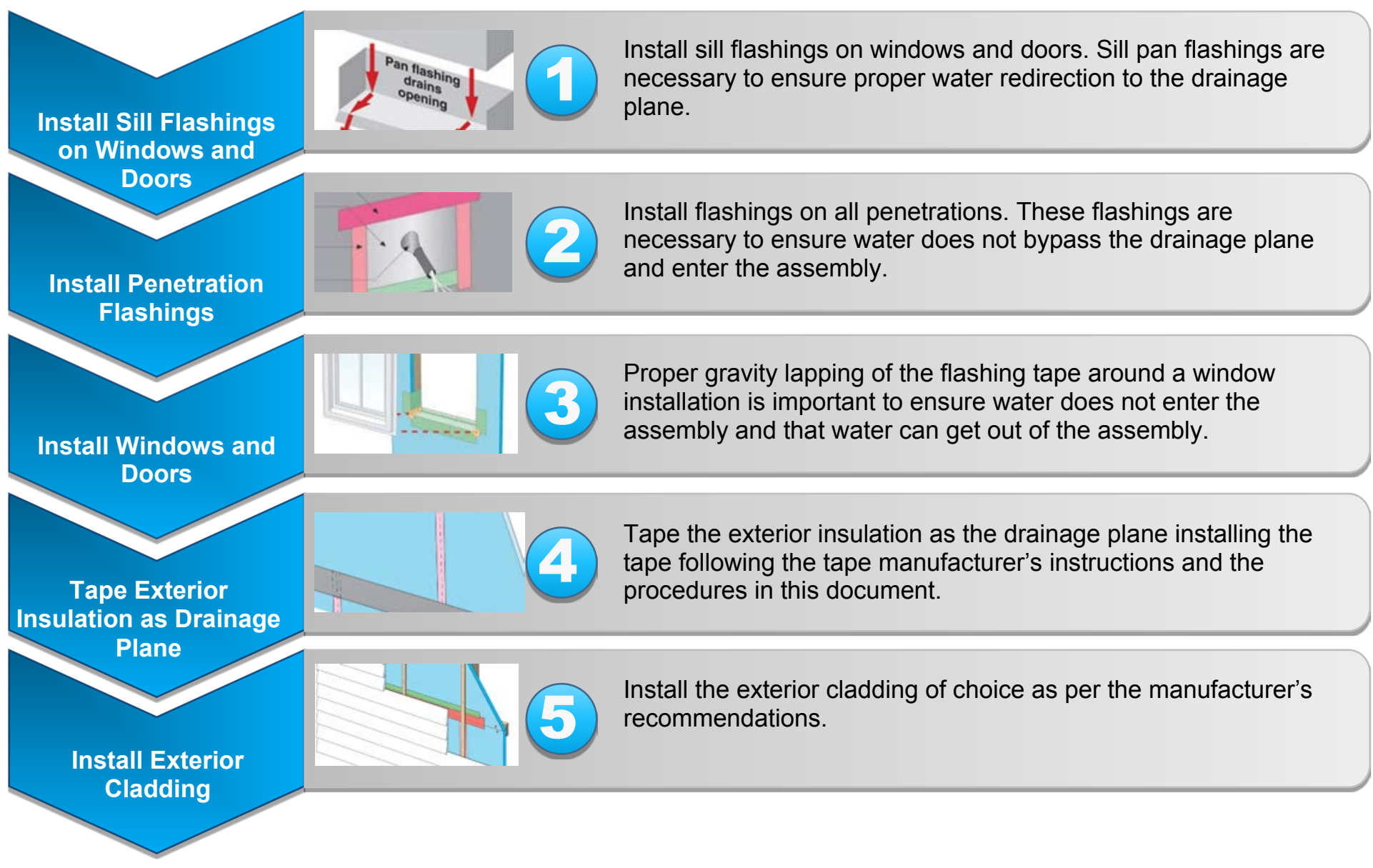




\section{Introduction}

The lowest cost, highest performing rainwater management strategy is rigid polymeric foam sheathing with sealed joints (Lstiburek 2006, 2010). There is an existing construction challenge of sealing the joints in rigid polymeric foam sheathing in a reliable and durable manner to prevent water ingress. This research provides simple, long-term, and durable solutions to the water intrusion issues that are possible by using tapes and membranes as integral portions of the drainage plane of the wall system. The knowledge gained from this research will be used in future Building America construction prototypes and well as other residential construction projects to increase the long-term moisture related durability of the enclosure, and reduce the risk of liquid water intrusion.

Sustainability is not possible without durability; if you double the life of a building and you use the same amount of resources to construct it, the building is twice as resource efficient. Therefore, durability is a key component of sustainability. It seems that one thing that both the development community and the environmental community can agree on is that durability is a good thing. The lessons of durability have come principally out of failure. Engineering is an iterative process of design by failure. Buildings are constructed. Problems are experienced. Designs and processes are changed. Better buildings are constructed. The building industry is in essence a reactive industry, not a proactive industry. It can be argued that the industry continues to do things until they become intolerably bad and then the industry changes. Examining failures gives us guidance on increasing the durability of building constructions. (BSD - 144)

Taping and sealing of joints in insulating sheathing has been occurring for more than two decades. Some failures and many successes have been reported over this time frame. A survey of existing installations, installers, contractors, and builders was conducted to determine the factors of success and failure. The recommendations are being refined using laboratory testing and field exposure testing. The exposure testing and feedback from contractors may be used to help or direct the development of new and refinement of current products. The survey provides insight into how builders across the country make taped insulating sheathing a simple, long-term, and durable drainage plane.

The team members involved with this project include members from Building Science Corporation, BASF, Dow, and DuPont. 


\section{Decision-Making Criteria}

Overall, the goal of the U.S. Department of Energy's Building America program is to "reduce home energy use by 30\%-50\% (compared to 2009 energy codes for new homes and pre-retrofit energy use for existing homes)." To this end, we conduct research to "develop market-ready energy solutions that improve efficiency of new and existing homes in each U.S. climate zone, while increasing comfort, safety, and durability."

Using exterior board foam insulation as part of a whole-house retrofit package can be a very effective method to reduce heat loss through the wall system by aiding in achieving the energy use reduction goals of the U.S. Department of Energy. Sealing the face of certain board foam insulation products can create an effective and code-approved drainage plane. Some moisturerelated ingress failures due to failed joints have occurred in using this system, prompting the necessity to develop further recommendations to improve the durability of the system.

\section{Cost and Performance}

It is difficult to assign a cost to durability, but the costs and associated issues that occur with enclosure failures resulting in moisture durability issues are very high. Our experience with many production homebuilders in the United States has provided us with anecdotal evidence that the costs (on average) to repair a house, have increased an order of magnitude from approximately $\$ 10010$ years ago, to approximately $\$ 1500$ today, largely as a result of water management issues. Because this is an average, and some houses have no reported problems, the houses that do have problems cost significantly more than $\$ 1500$. This increase in costs is also related to an order of magnitude increase in the incidences of water management issues in the last decade from poorly installed and detailed water management systems.

According to discussions during the survey of builders responsible for more than 27,000 homes in 2011 the following cost related information is summarized. Most builders found when comparing taped insulating sheathing to installing a sheet weather barrier system, both methods had approximately the same total installed cost. The labor and material costs, when considering a whole house, were roughly the same. The decision to choose one method over the other generally is not made based on the cost of installation. One builder has found with continued use of taped insulating sheathing as the drainage plane that a cost savings has developed. As a secondary benefit, some builders have seen an improvement in whole house airtightness as a result of using taped insulating sheathing as the drainage plane.

\section{Risk Identification}

The builder survey indicated that taped insulating sheathing as the drainage plane has little to no risk when the correct materials are used and the installation is completed in a careful manner. Careless installation or improperly selected materials may result in issues. Each builder insisted that frequent installation inspection and regular trade training are required to maintain proper installation. The methods shown in Section 5 are the best practice recommendations that minimize risk according to industry experience. Attachment A contains the International Conservation Code evaluation showing taped foam plastic insulating sheathing as a code compliant water-resistive barrier. 


\section{Technical Description}

The following research questions will be answered by this project.

- What materials are available for this purpose? What are the characteristics of these materials?

- Which new materials meet the performance requirements for water management with insulating sheathing?

- What is the experience of installers in all climates?

The performance of the taped sheathing system relies on material durability and system durability. The material durability component refers to the tape. The system durability component refers to the taped insulating sheathing as the drainage plane. Contractors have a unique perspective on these products and systems as they have first-hand experience in the site preparation and application. They also have an opportunity to see how the materials interact and perform over short time periods (e.g., during construction) and over longer time periods (e.g., through callbacks). Several contractors have implemented their own grass roots experimental programs to assess the buildability, performance, and durability of new products and systems. There is a need for researchers and product manufacturers to work with these contractors. An important first step is to document their experience, then to apply building science in the interpretation of the testing and to participate in the development of future products and testing. 


\section{Recommended Best Practices}

Little argument should remain in the industry over the energy efficiency-based financial benefits of adding exterior insulation. Using the exterior insulation as the drainage plane, removing the necessity to install a sheet or liquid applied weather barrier is the next logical step. Field implementation and durably taping the joints in the insulation in a repeatable manner are discussed in Section 5.

To bring together the experience of the nation, six homebuilders were interviewed who represent the experience of building more than 27,000 homes in 2011. Many of the recommendations from the homebuilders were in the form of recommended products or material properties (primarily adhesives). Installation methods and design recommendations are also included.

\section{Penetration Details}

In terms of window, door, and penetration flashing methods, most of the contractors and builders agreed that these details are already available and that using the right material and maintaining trade training and supervision were all that was required for success.

Flashings details are included in the following documents available online at www.buildingscience.com:

- Water Management Details - Housewraps/Flashings/Windows

- Building Science Information Sheet 303 - Common Flashing Details

- Building Science Digest-013 - Rain Control in Buildings

- Building Science Digest-105 - Understanding Drainage Planes

- Building Science Digest-144 - Increasing the Durability of Buildings.

More details are available in these books by Building Science Press:

- Water Management Guide

- Each of the climate-specific Builder's Guides.

In addition, almost all tape or flashing product manufacturers have, or are building, their own inhouse drawings, which depict their recommended installation methods.

Some of the most important penetrations to properly flash and drain are windows and doors. It is crucial to the durability of an assembly to install all windows and doors in a subsill pan flashing. All windows leak through their frames eventually and it is important that this water be properly directed outside the enclosure system. Figure 1 shows how the window or door is to sit in the pan flashing, Figure 2 shows three methods of creating the subsill pan flashing. The full process to install and flash the window is shown in Figure 3 through Figure 11. These same details shown can be applied to a door. 


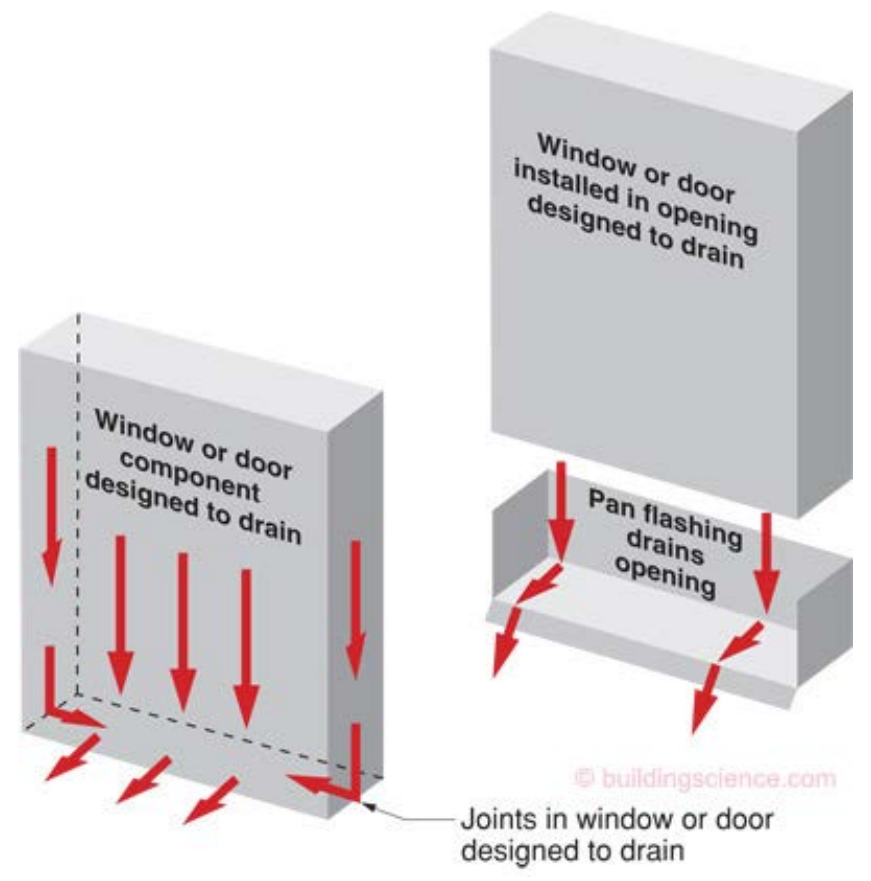

Figure 1. Pan flashing to drain openings
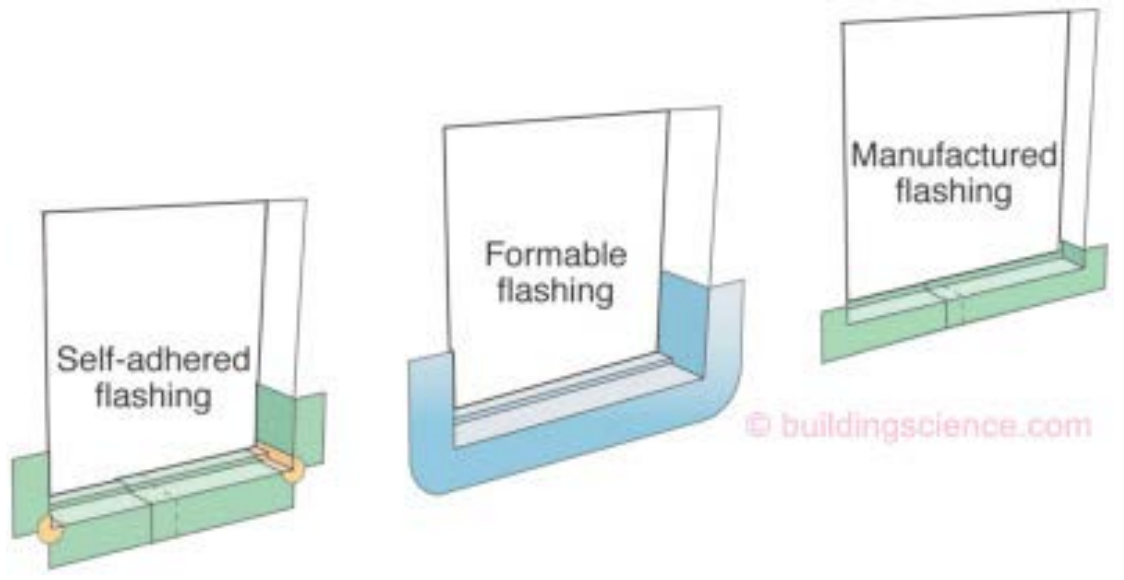

Figure 2. Types of pan flashing 

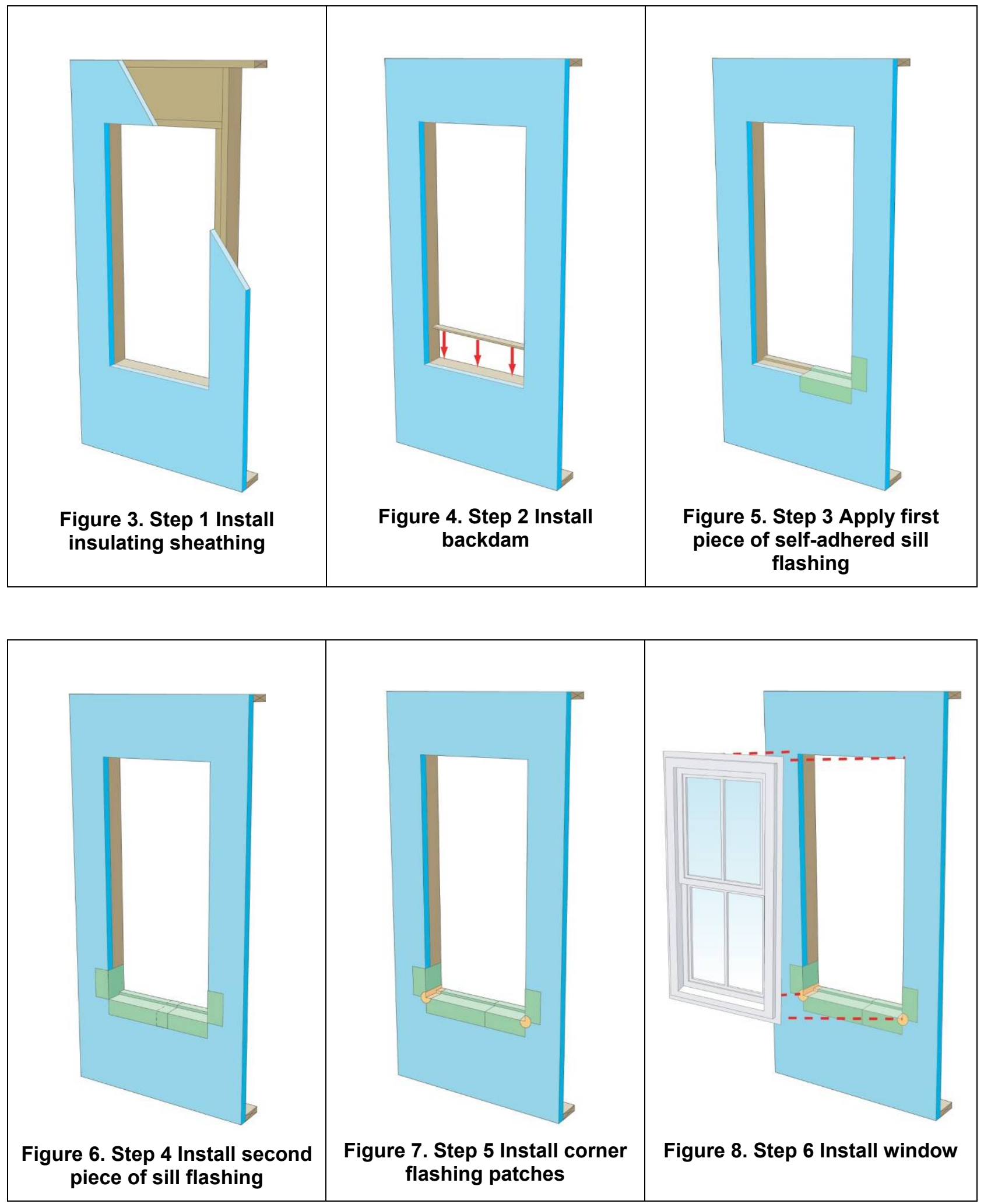


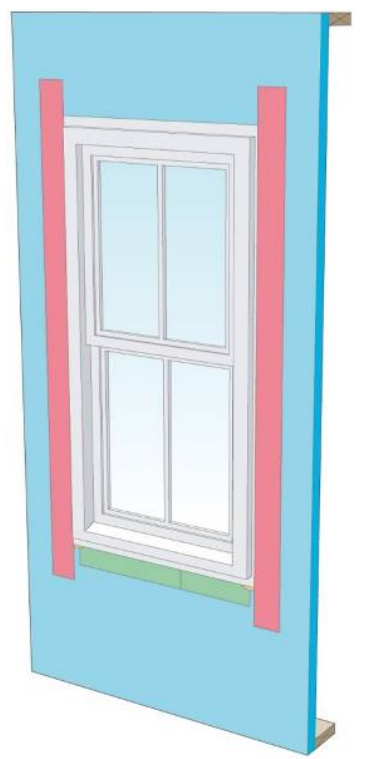

Figure 9. Step 7 Install selfadhered jamb flashing

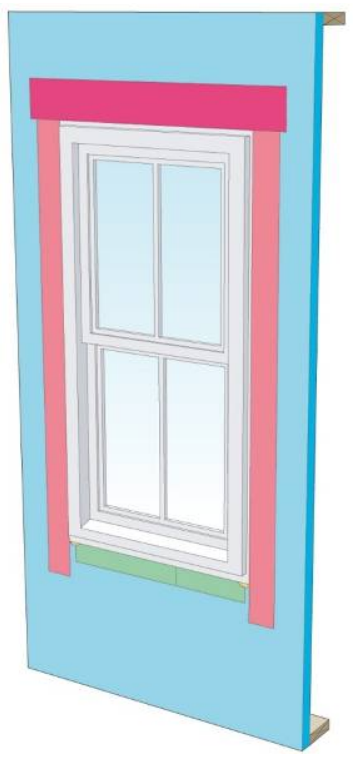

Figure 10. Step 8 Install selfadhered head flashing

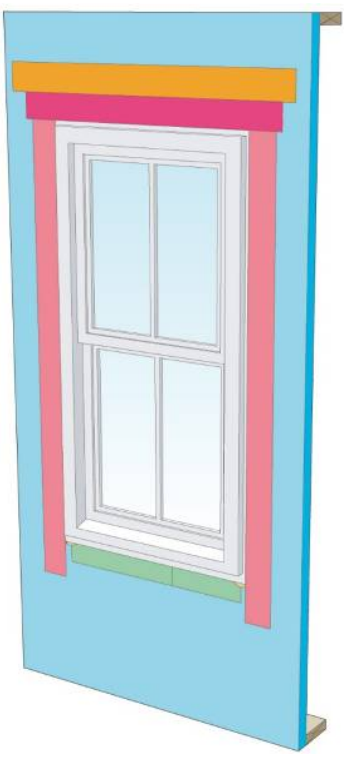

Figure 11. Step 9 Termination tape top edge of head flashing

Other key details covered in more detail in the recommended documents include penetrations as well as intersections between roofs and walls. An example roof to wall detail is shown in Figure 12.

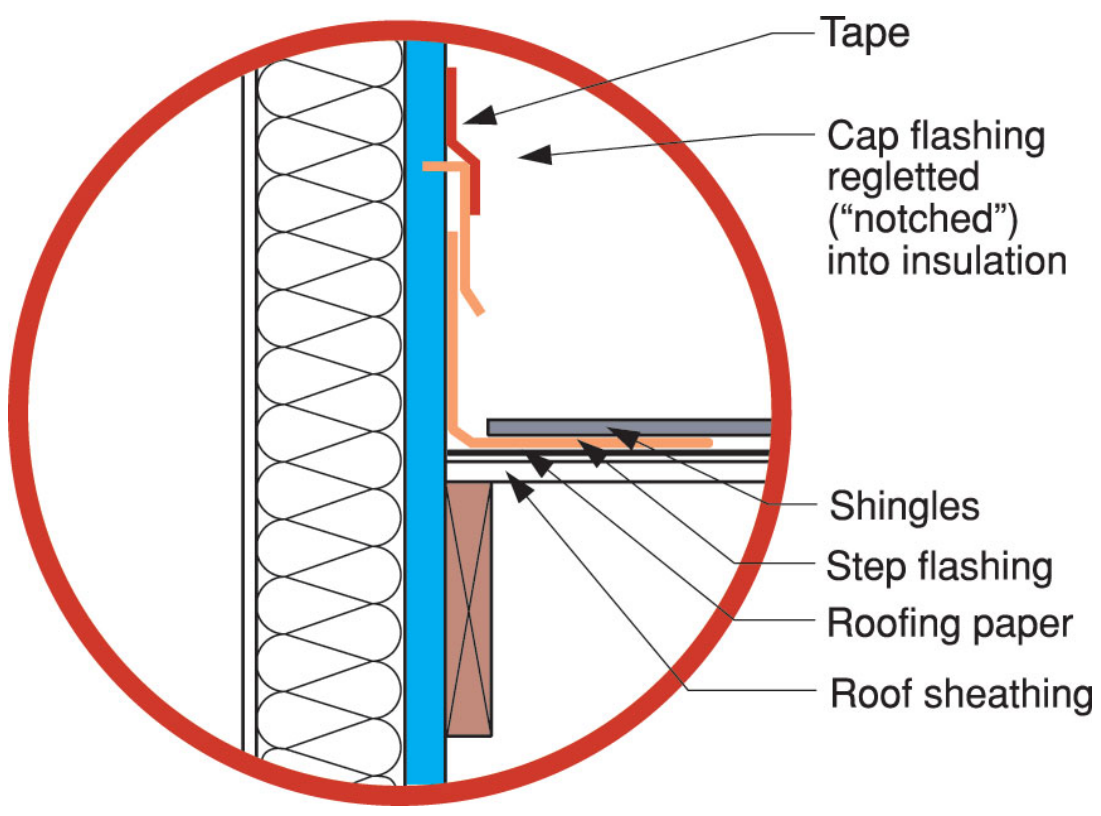

Figure 12. Roof to wall intersection 
Insulating Sheathing Joint Requirements, Recommendations, and Tape Materials The following are best practice and product recommendations from the interviewed contractors and homebuilders who collectively have a vast amount of experience. Three significant items were discussed with the group, which are required to make taped insulating sheathing a simple, long term, and durable drainage plane:

1. Horizontal joints should be limited or eliminated wherever possible.

2. Where a horizontal joint exists use superior materials.

3. Frequent installation inspection and regular trade training are required to maintain proper installation.

Where horizontal joints cannot be avoided, it was recommended by all contractors that cheap/poor/inferior products and methods should be avoided. This includes using tapes that are not designed as sheathing tapes, using thin polyethylene as Z-flashing, installing narrow tape, not following the manufacturer's guidelines as to surface preparation, etc. In their experiences, it is not worth the risk to save the few dollars to be found in buying the cheap tape materials or using short-cut methods and hoping they do not fail.

Each group interviewed had specific opinions on what methods and products produced a successful taped insulating sheathing drainage plane. All of the groups have used taped insulating sheathing as the drainage plane, although not all groups currently use this method. The following is a summary of the homebuilder's opinions and recommendations:

- A superior thin tape is:

- Acrylic adhesive based.

- Available in wide widths up to 4 in.

- Through experience be able to adhere to almost any substrate with high reliability in a range of climatic situations.

- Have good temperature and UV resistance.

- Available nationwide at a competitive price.

- A superior flashing tape is:

○ Butyl adhesive based.

- Not more than 20 mil thick (ensures overlaps do not build up too much)

○ Available in 6-9-in. widths.

- Have a facer that is very expansion/contraction compatible with its adhesive substrate.

- Have a facer that is no wider than the adhesive as to not trap water.

- Through experience be able to adhere to almost any substrate with high reliability in a range of climatic situations. 
- Have good temperature and UV resistance.

- Available nationwide at a competitive price, although builders would pay a premium for a product that repeatedly performed reliably.

- Foil tapes rip easily, and their backer materials are sometimes difficult to deal with.

- Foil tapes can have the tendency to "walk off" their substrates over time.

- Drainage planes must be:

- Smooth or not significantly textured

○ Clean

○ Dust free

- Ideally warm

- Tapes must be:

○ Clean

○ Dust free

○ Ideally warm

- Z-flashings should be used on any high-risk horizontal joint (Figure 13).

- Contractors who have walls with high water deposition and/or wind loads prefer to use Z-flashings for horizontal joints.

○ Some contractors use this method for all horizontal joints.

○ Butyl-based tapes 6-9 in. wide are preferred.

○ No contractor recommends using polyethylene sheet as a Z-flashing. 


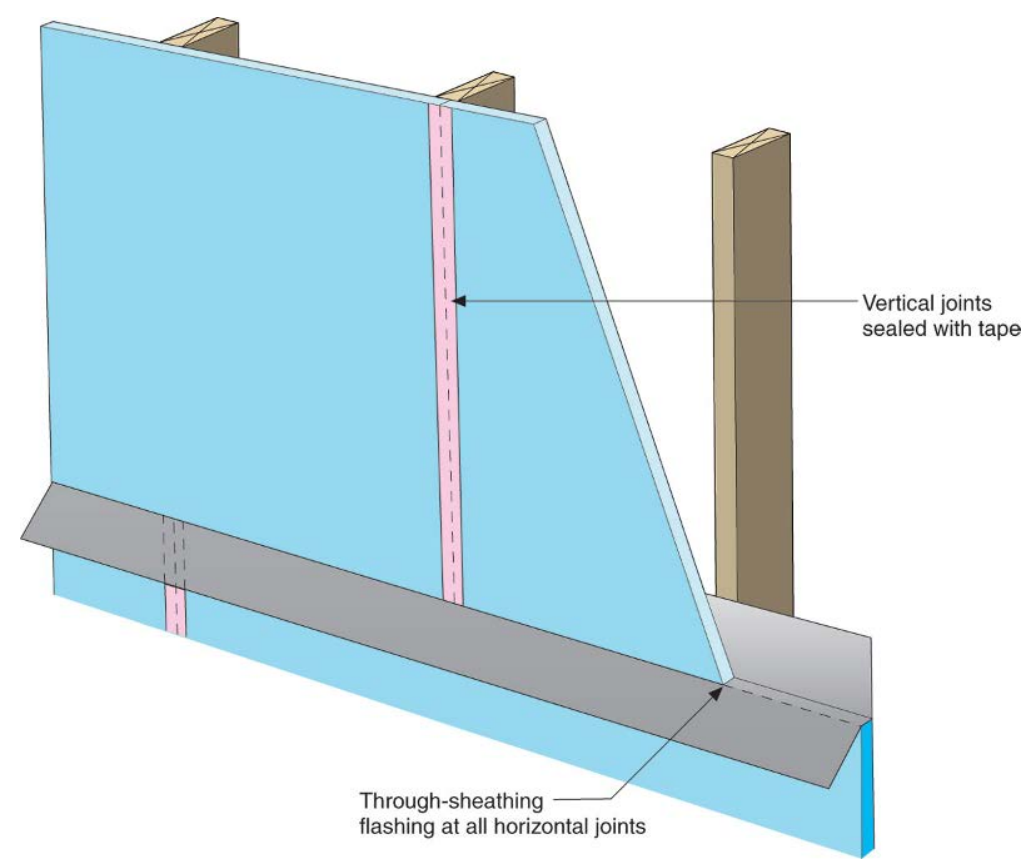

Figure 13. Example through drainage plane Z-flashing

- Where thick tapes (20-30 mil) are installed horizontally, a termination strip of thin tape should always be used (Figure 14).

- A tape termination strip is easier than a caulk termination strip.

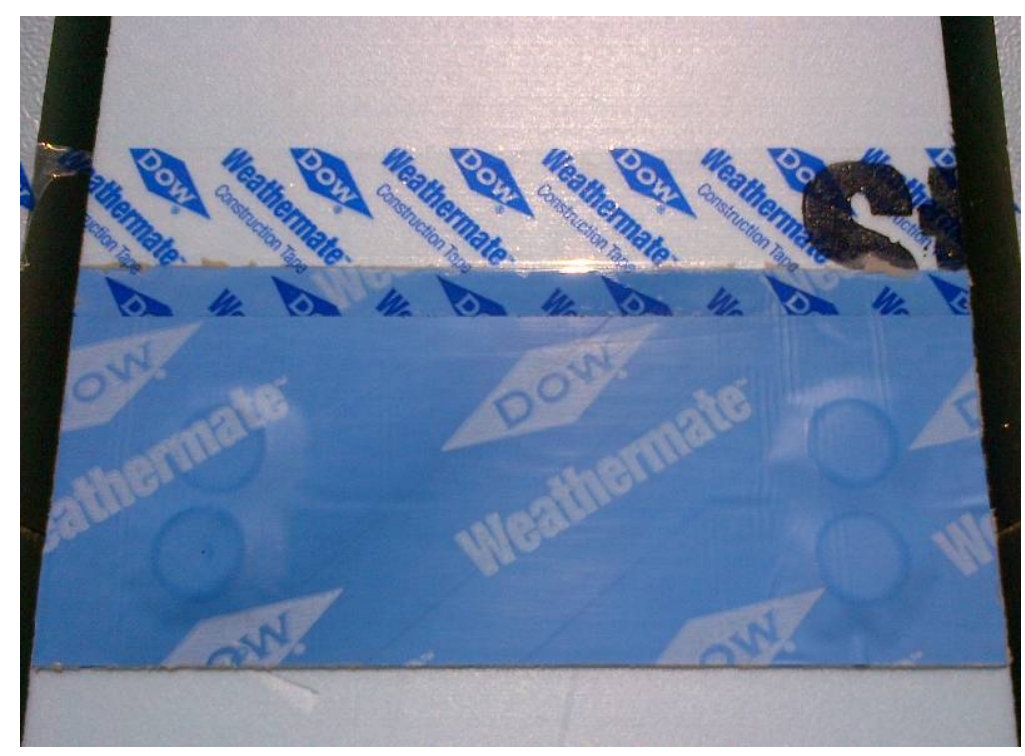

Figure 14. Example termination tape offset high on butyl tape 
- On horizontal joints, the tape should be offset favoring more tape and hence adherence to the upper sheet of substrate. In general, two thirds of the tape should be on the top sheet, and the remainder lapped over the bottom sheet (Figure 15).

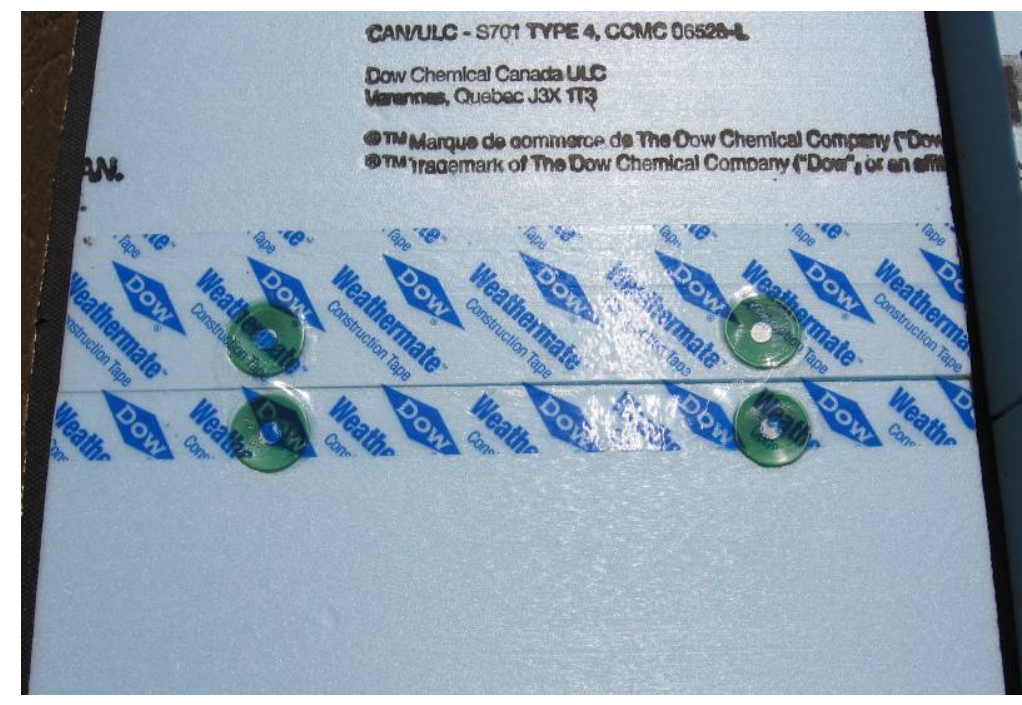

Figure 15. Example wide tape intentionally offset high

- Backup wood blocking should be installed behind horizontal joint locations.

○ Provides a backup and stiffness.

- Allows the perimeter of the sheet to be fastened properly.

- Provides support for when the tape is installed.

- In terms of flashing tapes, almost all groups interviewed prefer butyl base tapes over asphaltic based tapes.

- Vertical joints should land on framing members and be taped with a minimum 3-in. wide acrylic tape and gravity lapped with the horizontal joint.

In an effort to confirm the opinions of the homebuilders interviewed and provide some insight to the long-term lifespan of various tape materials, recommended for use in a taped insulating sheathing drainage plane, an outdoor exposure rack was developed and the tapes will be monitored over time. Details pertaining to the verification testing can be found in Appendix B.

Section 5 of this measure guideline contains the detailed construction procedure developed from the contractor recommendations. Three recommended methods are provided to effectively seal the joints in exterior insulating sheathing to create a simple, long-term, and durable drainage plane.

Attachment B contains links to the materials discussed and recommended in this measure guideline. 


\section{Construction Sequencing Details for Recommendations}

\section{GOOD-Basic Exterior Insulation Drainage Plane}

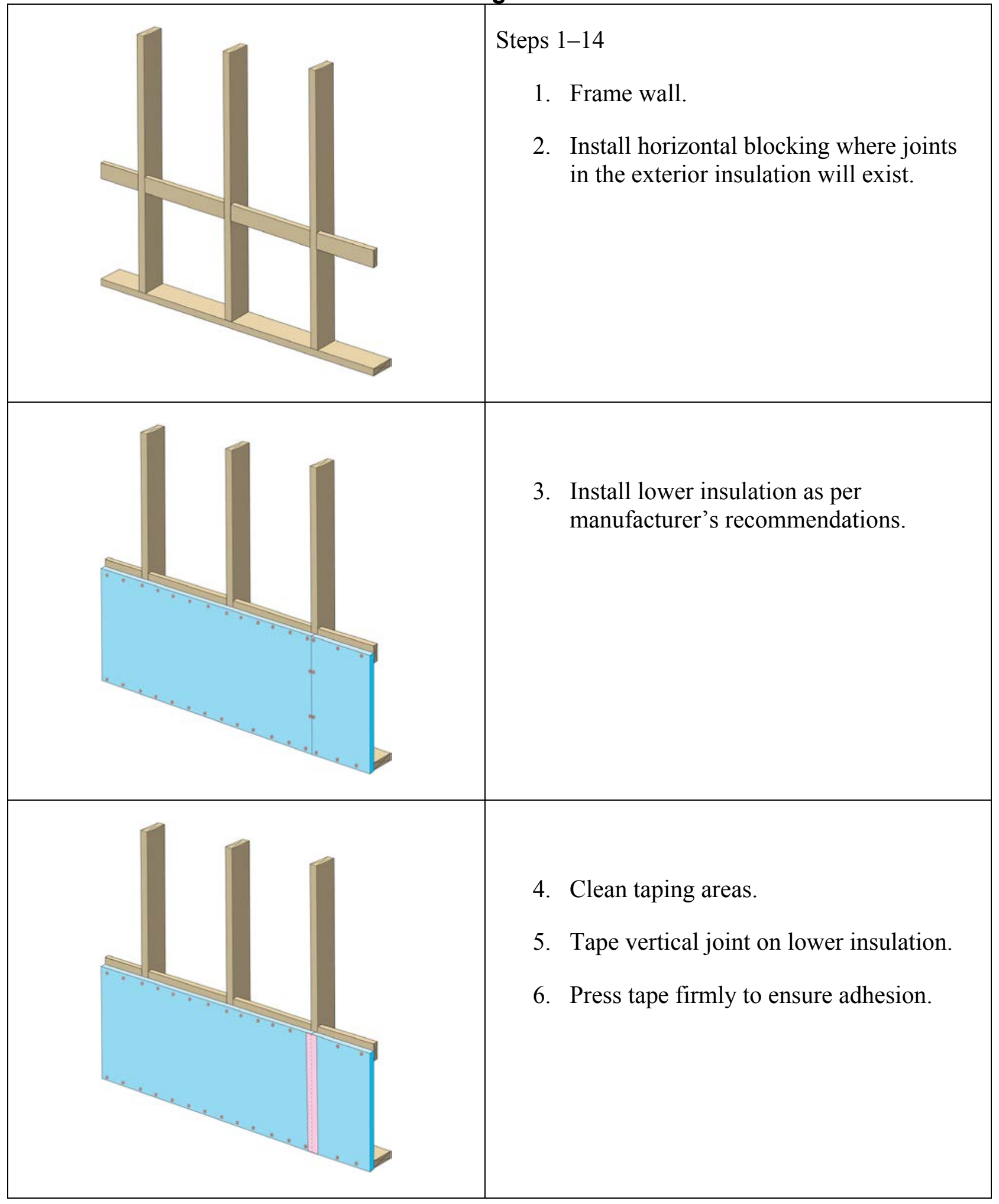




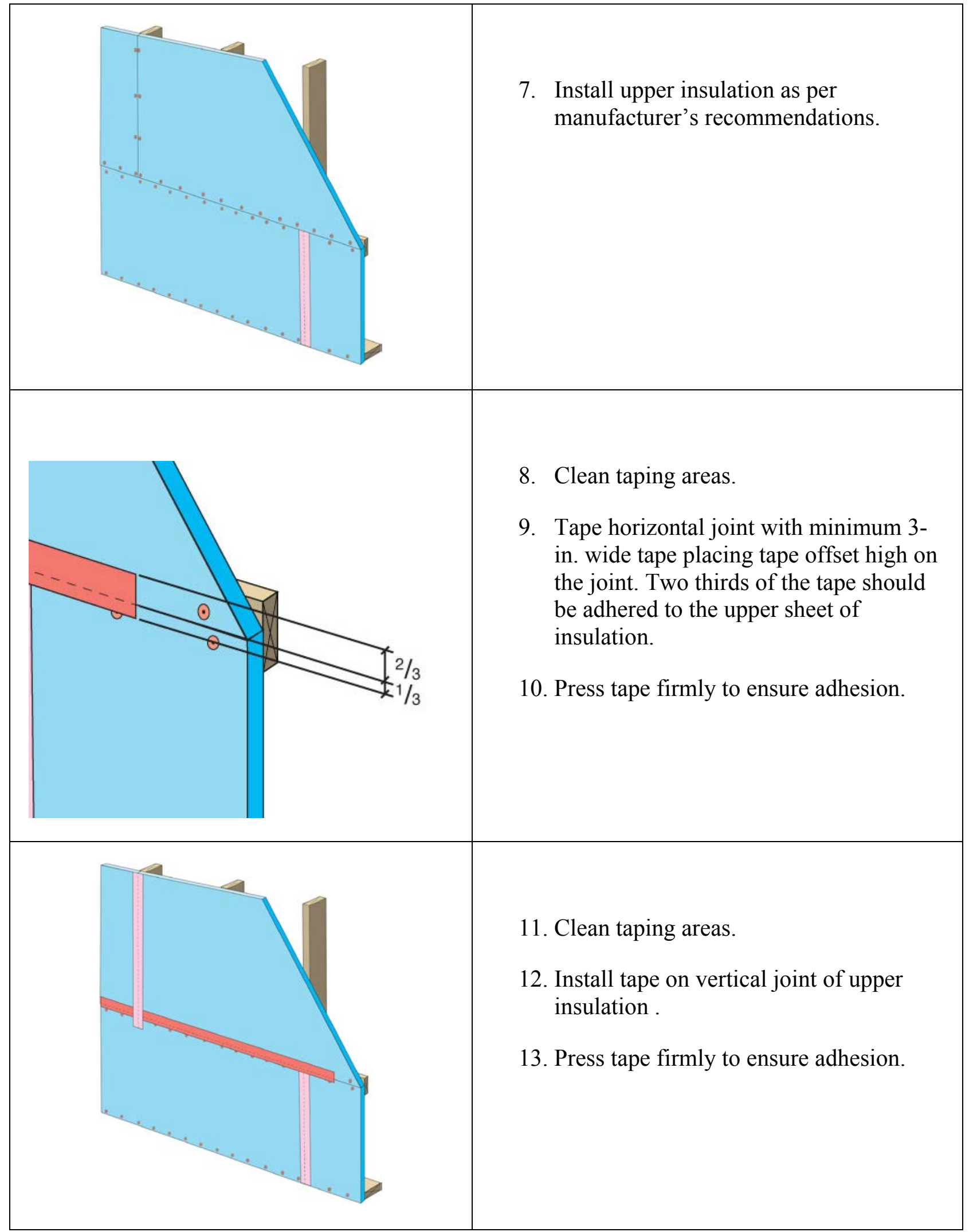




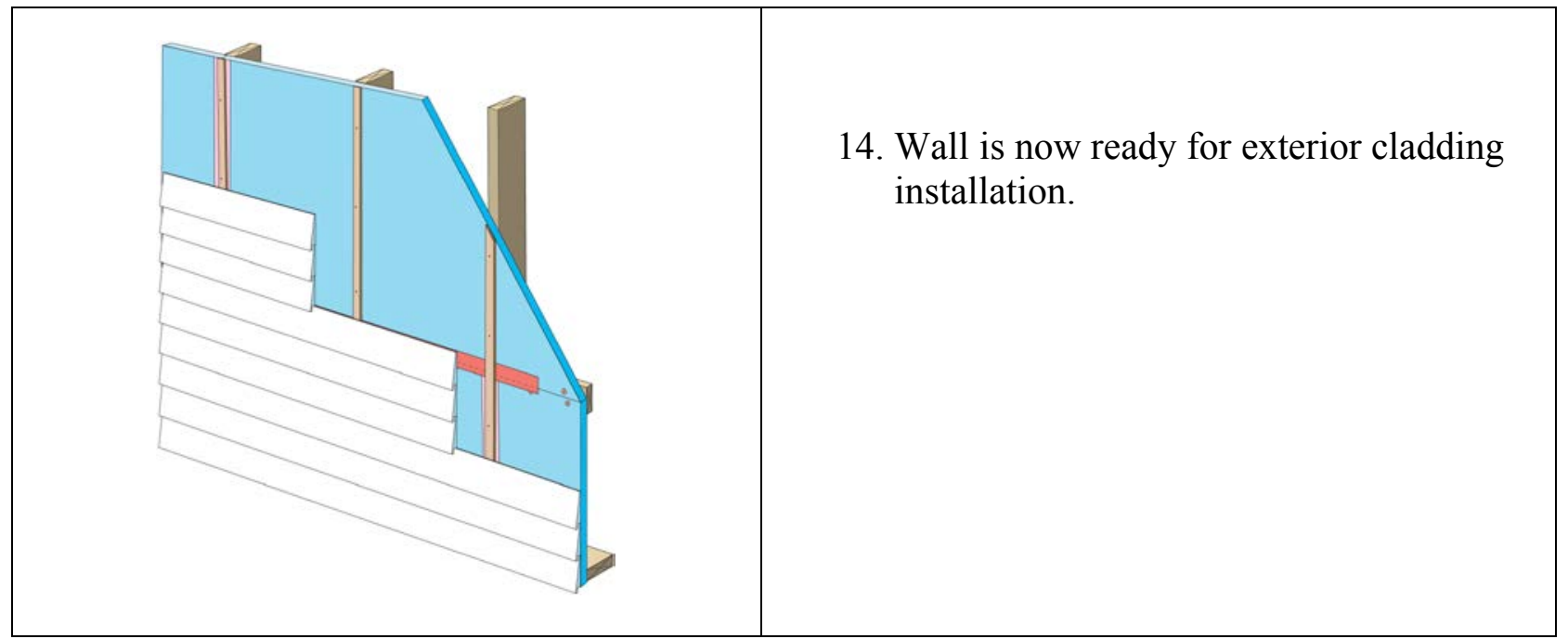




\section{BETTER-Improved Exterior Insulation Drainage Plane}

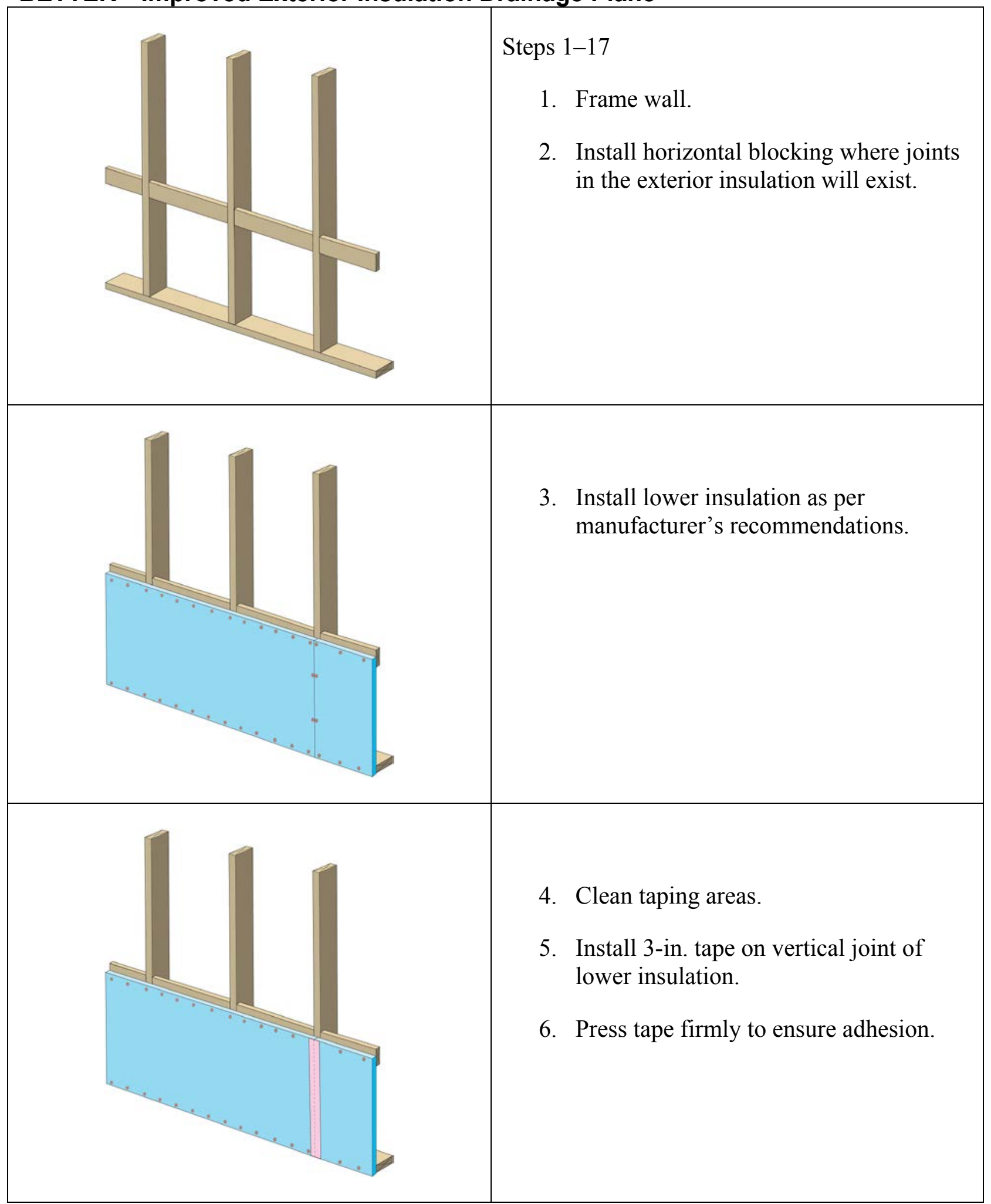




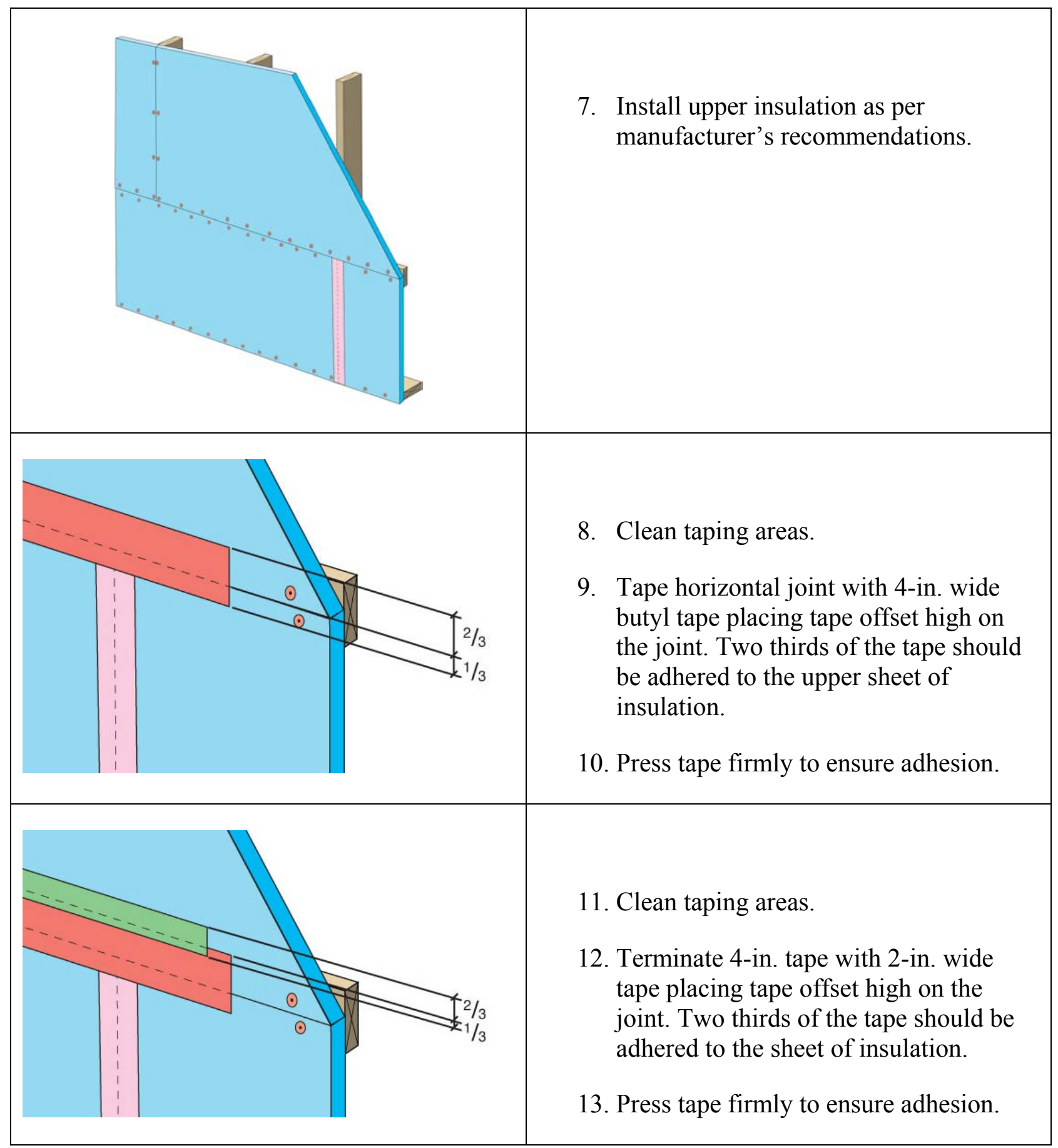




\begin{tabular}{|l|l|}
\hline $\begin{array}{l}\text { 14. Clean taping areas. } \\
\text { 15. Install 3-in. tape on vertical joint of } \\
\text { upper insulation overlapping the } \\
\text { horizontal joint. }\end{array}$ \\
$\begin{array}{c}\text { 16. Press tape firmly to ensure adhesion. } \\
\text { 17. Wall is now ready for exterior cladding } \\
\text { installation. }\end{array}$ \\
\hline
\end{tabular}




\section{BEST-Z-Flashed Exterior Insulation Drainage Plane}

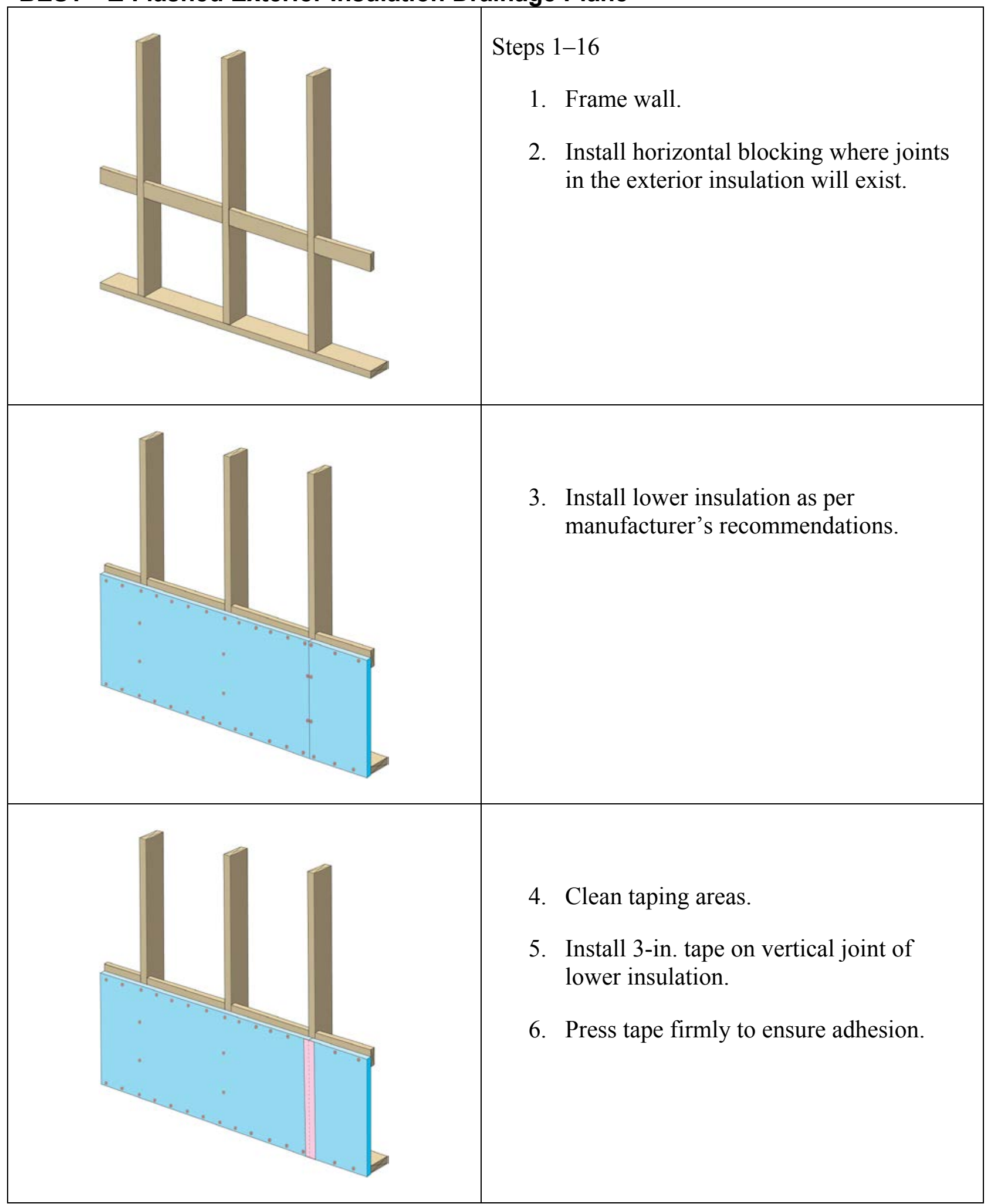




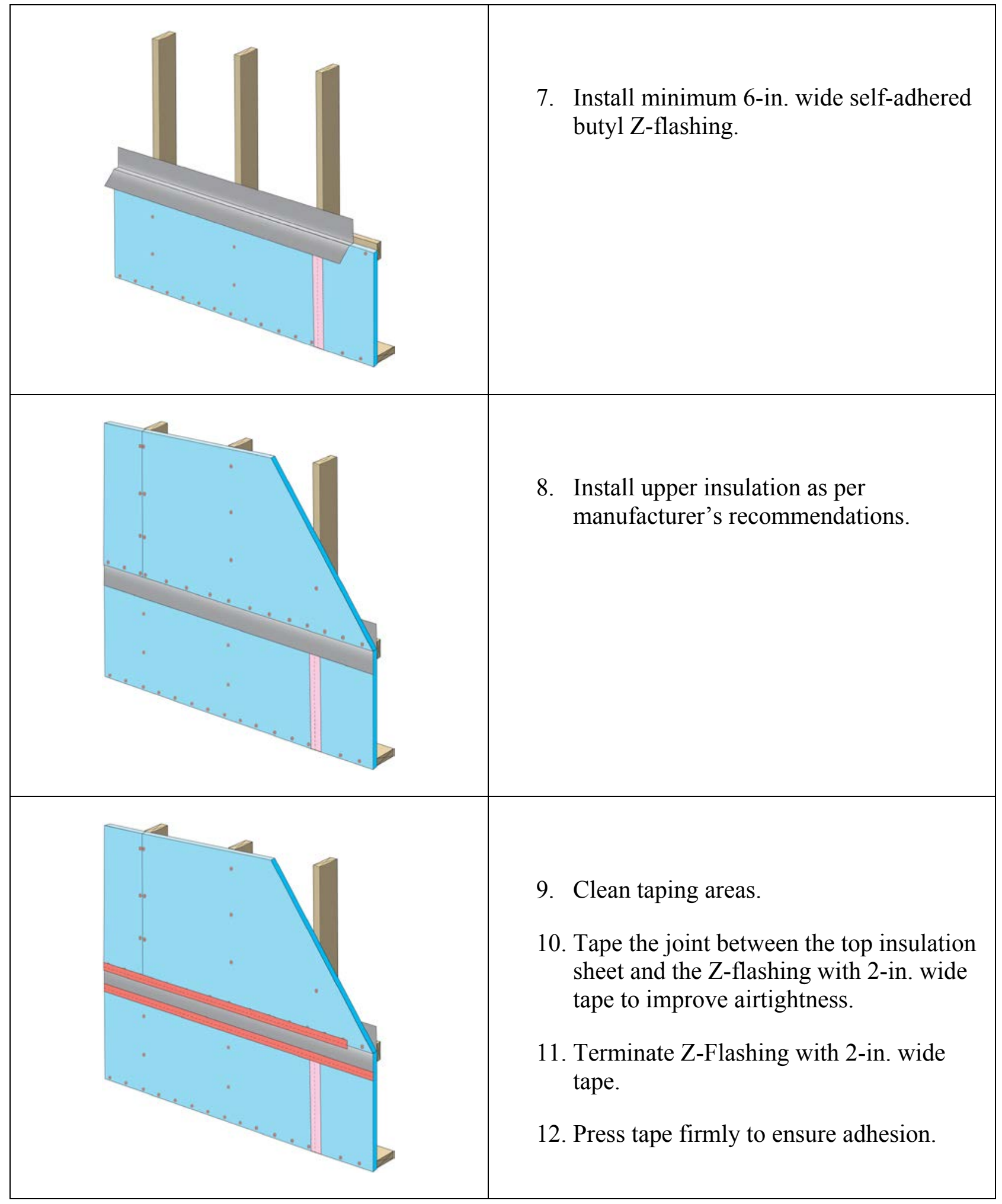




\begin{tabular}{|l|l|}
\hline $\begin{array}{l}\text { 13. Clean taping areas. } \\
\text { 14. Install 3-in. tape on vertical joint of } \\
\text { upper insulation overlapping the } \\
\text { horizontal joint. }\end{array}$ \\
$\begin{array}{c}\text { 15. Press tape firmly to ensure adhesion. } \\
\text { installation. }\end{array}$ \\
16. Wall is now ready for exterior cladding \\
ins
\end{tabular}




\section{Summary}

Questions 1 and 2: What materials are available for this purpose? What are the characteristics of these materials? Which new materials meet the performance requirements for water management with insulating sheathing?

Answer.

- A superior thin tape is:

- Acrylic adhesive based.

- Available in wide widths up to 4 in.

- Through experience be able to adhere to almost any substrate with high reliability in a range of climatic situations.

○ Have good temperature and UV resistance.

- Available nationwide at a competitive price.

- A superior flashing tape is:

○ Butyl adhesive based.

○ Not more than 20 mil thick (ensures overlaps do not build up too much).

○ Available in 6-, 9-, and 12-in. widths.

○ Have a facer that is very expansion/contraction compatible with its adhesive substrate.

- Have a facer that is no wider than the adhesive as to not trap water.

- Through experience be able to adhere to almost any substrate with high reliability in a range of climatic situations.

- Have good temperature and UV resistance.

- Available nationwide at a competitive price.

Question 3: What is the experience of installers in all climates?

Answers:

The following are best practice and product recommendations from the interviewed contractors and homebuilders who collectively have a vast amount of experience. Three items are required to make taped insulating sheathing a simple, long-term, and durable drainage plane:

1. Horizontal joints should be limited or eliminated wherever possible.

2. Where a horizontal joint exists use high quality materials.

3. Frequent installation inspection and regular trade training are required. 
The following is a summary of the homebuilders' opinions and recommendations on methods and products:

- On horizontal joints, the tape should be offset favoring more tape on the upper sheet of substrate. A decent rule is that two thirds of the tape should be on the top sheet, and the remainder lapped over the bottom sheet.

- Z-flashings can be used on all horizontal joints and should be used on any high-risk horizontal joint.

- Drainage planes and tapes must be smooth, clean, dust free, and ideally warm.

- A termination strip of thin tape should always be used for thick tapes.

- Backup wood blocking should be installed behind horizontal joint locations.

- Vertical joints should land on framing members and be taped with a minimum 3-in. wide acrylic tape and gravity lapped with the horizontal joint.

- In terms of flashing tapes, almost all groups interviewed prefer butyl-based tapes over asphaltic based tapes.

- Dow Weathermate is a thin tape product that was recommended by most homebuilders.

- Dow Weathermate Flashing is a flashing tape product that was recommended by most homebuilders. 


\section{Attachment A: Compliance}

International Code Council Evaluation Service - AC71 - Acceptance Criteria for Foam Plastic

Sheathing Panels Used as Water-Resistive Barriers 


\title{
ACCEPTANCE CRITERIA FOR FOAM PLASTIC SHEATHING PANELS USED AS WATER-RESISTIVE BARRIERS
}

\author{
AC71
}

Approved February 2003

Effective March 1, 2003

(Editorially revised March 2011)

Previously approved January 2002, June 2001, August 1966

\section{PREFACE}

Evaluation reports issued by ICC Evaluation Service, LLC (ICC-ES), are based upon performance features of the International family of codes and other widely adopted code families, including the Uniform Codes, the BOCA National Codes, and the SBCCI Standard Codes. Section 104.11 of the International Building Code reads as follows:

The provisions of this code are not intended to prevent the installation of any materials or to prohibit any design or method of construction not specifically prescribed by this code, provided that any such alternative has been approved. An alternative material, design or method of construction shall be approved where the building official finds that the proposed design is satisfactory and complies with the intent of the provisions of this code, and that the material, method or work offered is, for the purpose intended, at least the equivalent of that prescribed in this code in quality, strength, effectiveness, fire resistance, durability and safety.

Similar provisions are contained in the Uniform Codes, the National Codes, and the Standard Codes

This acceptance criteria has been issued to provide all interested parties with guidelines for demonstrating compliance with performance features of the applicable code(s) referenced in the acceptance criteria. The criteria was developed and adopted following public hearings conducted by the ICC-ES Evaluation Committee, and is effective on the date shown above. All reports issued or reissued on or after the effective date must comply with this criteria, while reports issued prior to this date may be in compliance with this criteria or with the previous edition. If the criteria is an updated version from the previous edition, a solid vertical line (|) in the margin within the criteria indicates a technical change, addition, or deletion from the previous edition. A deletion indicator $\rightarrow$ is provided in the margin where a paragraph has been deleted if the deletion involved a technical change. This criteria may be further revised as the need dictates.

ICC-ES may consider alternate criteria, provided the report applicant submits valid data demonstrating that the alternate criteria are at least equivalent to the criteria set forth in this document, and otherwise demonstrate compliance with the performance features of the codes. Notwithstanding that a product, material, or type or method of construction meets the requirements of the criteria set forth in this document, or that it can be demonstrated that valid alternate criteria are equivalent to the criteria in this document and otherwise demonstrate compliance with the performance features of the codes, ICC-ES retains the right to refuse to issue or renew an evaluation report, if the product, material, or type or method of construction is such that either unusual care with its installation or use must be exercised for satisfactory performance, or if malfunctioning is apt to cause unreasonable property damage or personal injury or sickness relative to the benefits to be achieved by the use of the product, material, or type or method of construction.

Acceptance criteria are developed for use solely by ICC-ES for purposes of issuing ICC-ES evaluation reports. 


\section{ACCEPTANCE CRITERIA FOR FOAM PLASTIC SHEATHING PANELS USED AS WATER-RESISTIVE BARRIERS (AC71)}

\subsection{INTRODUCTION}

1.1 Purpose: The purpose of this acceptance criteria is to establish requirements for foam plastic sheathing panels to be recognized in an ICC Evaluation Service, LLC (ICC-ES), evaluation report under the 2009 International Building Code (2009 IBC), the 2009 International Residential Code (2009 IRC), the 2006 International Building Code ${ }^{(2006}$ IBC), the 2006 International Residential Code (2006 IRC) and the 1997 Uniform Building Code ${ }^{\mathrm{TM}}$ (UBC). The bases of recognition are IBC Section 104.11, IRC Section R104.11and UBC Section 104.2.8

The reason for the development of this criteria is to establish test requirements that will permit the foam plastic sheathing panels to be used as water-resistive barriers in combustible construction, since the codes do not provide requirements for the material to be used in this manner.

1.2 Scope:

1.2.1 This criteria is limited to foam plastic insulation and associated joint sealing methods used on exterior walls as an alternative to the water-resistive barrier specified in Section 1404.2 of the IBC and Section R703.2 of the IRC; and the weather-resistive barrier specified in Section 1402.1 of the UBC.

1.2.2 This criteria is limited to foam plastic insulation recognized in a current ICC-ES evaluation report showing compliance with Sections 3.4 .1 or 3.4 .3 of the ICC-ES Acceptance Criteria for Foam Plastic Insulation (AC12)

1.2.3 This criteria does not address the use of the foam plastic insulation as structural sheathing, resisting in-plane or out-of-plane loadings

1.2.4 This criteria does not require reporting of the water vapor transmission properties of the foam plastic insulation.

1.3 Definitions:

1.3.1 Water-resistive Barrier: For the purposes of this criteria, the term "water-resistive barrier" includes within its scope water-resistive barrier under Section 1404.2 of the IBC, water-resistive barrier under Section R703.2 of the IRC and weather-resistive barrier under Section 1402.1 of the UBC.

1.3.2 Foam Plastic Sheathing Panels Used as Weather Resistive Barrier: Foam plastic boards, sheets, or panels, when installed on an exterior wall with joint sealing methods or treatments, are intended to prevent water intrusion into the wall cavity. These products may be faced or unfaced.

1.3.3 Joint-sealing Treatments: Joint-sealing treatments are tapes, or caulks, or materials that are used to seal joints that may occur between two or more edges of the foam plastic insulation

1.3.4 Joint-sealing Methods: Joint-sealing methods are mechanical edge treatments of foam plastic sheathing panels such as, but not limited to tongue and groove or ship-lapped edges.

1.4 Codes and Referenced Standards:

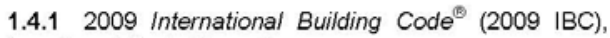
International Code Council.

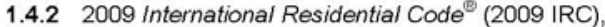
International Code Council.

1.4.3 2006 International Building Code ${ }^{(5)}$ (2006 IBC), International Code council

1.4.4 2006 International Residential Code ${ }^{(2)}$ (2006 IRC), International Code Council.

1.4.5 Uniform Building Code ${ }^{\mathrm{TM}}$.

1.4.6 ASTM E 331-00, Standard Test Method for Water Penetration of Exterior Windows, Skylights, Doors and Curtain Walls by Uniform Static Air Pressure Difference, ASTM International.

1.4.7 AATCC, Test Method 127-1998, Water Resistance: Hydro Static Pressure Test, American Association of Textile Chemists and Colorists.

\subsection{BASIC INFORMATION}

2.1 General: The following information shall be submitted:

2.1.1 Product Description: Complete information concerning material specifications, thickness, size and the manufacturing process shall be submitted for the foam plastic insulation. Information concerning joint treatment materials, including manufacturer and material specifications, shall be provided.

2.1.2 Installation Instructions: Installation details and limitations, fastening methods, joint treatments, and face treatments.

2.1.3 Packaging and Identification: A description of the method of packaging and field identification of the system components. Identification provisions on the foam plastic insulation and on proprietary treatment materials shall include the evaluation report number and the name or logo of the inspection agency.

2.1.4 Field Preparation: A description of the methods of field-cutting, application and finishing.

2.2 Testing Laboratories: Testing laboratories shall comply with Section 2.0 of the ICC-ES Acceptance Criteria for Test Reports (AC85) and Section 4.2 of the ICC-ES Rules of Procedure for Evaluation Reports, and shall be accredited for the scope of tests covered by this criteria.

2.3 Test Reports: Test reports shall comply with AC85.

2.4 Product Sampling: Products for testing shall be sampled in accordance with Section 3.2 of AC85. Upon submission of initial, qualifying test data to ICC-ES, the manufacturer shall submit an affidavit certifying that the product tested is representative of the standard manufactured product for which recognition is being sought. Alternately, the manufacturer may choose to have the product sampled independently by an accredited inspection agency (in lieu of the affidavit)

\subsection{TEST AND PERFORMANCE REQUIREMENTS}

Reports of the following tests shall be submitted:

3.1 Foam Plastic Insulation-Water-resistance:

3.1.1 Water-resistance testing shall be conducted on the foam plastic insulation for which recognition is sought.

3.1.2 Three specimens [each 8 inches (203 mm) square] of the foam plastic insulation shall be at the minimum thickness and density intended for use and be 
ACCEPTANCE CRITERIA FOR FOAM PLASTIC SHEATHING PANELS USED AS WATER-RESISTIVE BARRIERS (AC71)

faced (if facers are used) with the material for which recognition is sought.

3.1.3 The test specimens shall be weathered in accordance with Section 3.5 of this criteria.

3.1.4 Water-resistance tests shall be conducted on the weathered specimens in accordance with AATCC Test Method 127. Testing in accordance with AATCC Test Method 127 shall be such that the specimens shall be held at a hydrostatic head of 21.6 inches $(55 \mathrm{~cm})$ for a period of 5 hours.

3.1.5 Conditions of Acceptance: Weathered specimens shall not exhibit water leakage on the underside of any specimen.

3.2 Joint-sealing Treatments:

3.2.1 General: Joint-sealing treatments shall meet the requirements of Section 3.2 .2 and 3.4 of this criteria. Testing shall be conducted for each type of joint with respect to the substrate materials that form foam-to-foam or foam-to-flashing joints.

3.2.2 Three specimens of each joint-sealing treatment are required. The test specimens shall be prepared with 3-inch-by-6-inch ( $76 \mathrm{~mm}$ by $152 \mathrm{~mm}$ ) pieces of the foam plastic insulation and the joint sealing treatments for which recognition is being sought. Each specimen includes the two pieces of substrate materials aligned so that the 6 -inch $(152 \mathrm{~mm})$ edges are butt-jointed. The joint-sealing treatment is applied to the pieces along the 6 in. $(152 \mathrm{~mm})$ dimension of the joint. The sample joint shall be unbacked unless recognition is sought for other joint constructions.

3.2.3 The joint-sealing treatment specimens shall be exposed to the weathering conditions of Section 3.5 of this criteria.

3.2.4 Water-resistance tests shall be conducted on the weathered specimens in accordance with AATCC Test Method 127. Testing in accordance with AATCC Test Method 127 shall be such that the specimens shall be held at a hydrostatic head of 21.6 inches $(55 \mathrm{~cm})$ for a period of 5 hours. Testing shall be conducted such that the joint treatment is exposed to the hydrostatic head. In the case of tapes, the hydrostatic head shall be positioned over both the joint area and the interface of the tape and the foam insulation.

3.2.5 Conditions of Acceptance: Weathered specimens shall not exhibit water leakage on the underside of any specimen.

3.3 Joint-sealing Methods: Joint-sealing methods that incorporate tongue and groove, ship-lap joints or similar methods without treatments, shall be evaluated using Section 3.4 of this criteria.

3.4 Water Penetration Test of Wall Assembly:

3.4.1 General: Tests shall be conducted on a wall assembly containing the foam plastic insulation with joint sealing methods or treatments applied to framing in accordance with IBC Section 1403.2, Exception 2, and ASTM E 331, as follows:

3.4.1.1 Test assemblies shall be at least 4 feet wide by 8 feet high $(1219 \mathrm{~mm}$ by $2438 \mathrm{~mm})$ in size. The foam plastic sheathing panels as well as the joint sealing treatments or methods shall be installed in the manner for which recognition is sought. Assemblies shall include at least one vertical joint representative of normal installation methods. When recognition is sought for horizontal joints, assemblies shall include at least two horizontal joints. All joints shall be unbacked unless other specific recognition is sought.

3.4.1.2 The assemblies shall be tested without exterior wall coverings. Openings or penetrations in the test assemblies are not required. When the assembly is tested with openings and penetrations, Section 4.2 of this criteria shall not apply.

3.4.1.3 The test assemblies shall be tested at a minimum differential pressure of $6.24 \mathrm{psf}\left(0.297 \mathrm{kN} / \mathrm{m}^{2}\right)$.

3.4.1.4 The test assemblies shall be subjected to a minimum test exposure duration of 2 hours.

3.4.1.5 3.4.1.5 Conditions of Acceptance: Water shall not penetrate to the unexposed face of the foam plastic insulation.

3.5 Weathering Tests:

3.5.1 When weathering tests are required by Section 3.1 or 3.2 of this criteria, specimens shall be subjected to ultraviolet light exposure in accordance with Section 3.5 .2 followed by accelerated aging in accordance with Section 3.5.3.

3.5.2 Ultraviolet Light Exposure: Samples shall be exposed to light from ultraviolet sun lamps for 210 hours (10 hours per day for 21 days). Ultraviolet light exposure shall be directed on the sample surfaces that will be exposed to sunlight in normal application. Lamps and enclosure shall be adjusted so the specimen temperature is between $135^{\circ} \mathrm{F}$ and $140^{\circ} \mathrm{F}\left(57^{\circ} \mathrm{C}\right.$ and $\left.60^{\circ} \mathrm{C}\right)$. Sunlamp bulbs shall be General Electric Type H275 RUV (275 W) or equivalent bulbs, providing UV characteristics of 5.0 $W / \mathrm{m}^{2} / \mathrm{nm}$ irradiance at a wavelength of 315 to $400 \mathrm{~nm}$ at 1 meter.

3.5.3 Accelerated Aging: The specimens shall be subjected to 25 cycles of drying and soaking as follows

1. Oven drying at $120^{\circ} \mathrm{F}\left(49^{\circ} \mathrm{C}\right)$ for three hours, with all surfaces exposed.

2. Immersion in room-temperature water for three hours, with all surfaces exposed.

3. After removal from the water, specimens are blotted dry, then air-dried for 18 hours at a $75^{\circ} \mathrm{F} \pm 5^{\circ} \mathrm{F}$ $\left(23.8^{\circ} \mathrm{C} \pm 2.8^{\circ} \mathrm{C}\right)$ room temperature, with all surfaces exposed

3.5.4 Conditions of Acceptance: There shall be no visible delamination or blistering of the facing layer. Additionally specimens must be subjected to the water resistance test described in Sections 3.1 and 3.2.

\subsection{SPECIAL REQUIREMENTS}

4.1 For the IBC, IRC and UBC, a vapor retarder complying with Section 1405.3 of the 2009 IBC, Section 1403.2 of the 2006 IBC, Section R6013 of the 2009 IRC or Section R318.1 of the 2006 IRC shall be installed on the warm-in-winter side of the wall.

4.2 When the system has not been tested in accordance with Section 3.4 with penetrations and openings, the evaluation report on the foam plastic insulation shall require the foam plastic to be specifically recognized in a current ICC-ES evaluation report on a wall covering 
ACCEPTANCE CRITERIA FOR FOAM PLASTIC SHEATHING PANELS USED AS WATER-RESISTIVE BARRIERS (AC71)

system. The evaluation report on the wall covering system shall provide flashing details specific to the foam plastic insulation, and the wall covering system incorporating the foam plastic insulation shall be tested in accordance with IBC Section 1403.2, Exception 2.

\subsection{QUALITY CONTROL}

5.1 Joint-sealing Treatment: Joint-sealing treatments are required to be manufactured under a quality control program documented in accordance with the ICC-ES Acceptance Criteria for Quality Documentation (AC10).
Follow-up inspections by an inspection agency are not required under this criteria.

5.2 Foam Plastic: All foam plastic boards shall be listed and labeled as set forth in Section 2603.2 of the IBC, Section R316.2 of the 2009 IRC, Section R314.2 of the 2006 IRC, or Section 2602.2 of the UBC. Compliance of foam plastic is based on a current applicable evaluation report, on the foam plastic, issued by ICC-ES; if no such report exists, foam plastic shall comply with the ICC-ES Acceptance Criteria for Foam Plastic Insulation (AC12). 


\section{Attachment B: Product Materials}

Dow Weathermate Tape, Weathermate Flashing Tape, and Foil Tapes

Link - http://building.dow.com/na/en/products/specialty/accessories.htm

DuPont Tyvek Tape and Straightflash

Link -

http://www2.dupont.com/Tyvek_Weatherization/en_US/products/residential/resi_accessories.ht $\underline{\mathrm{ml}}$

Henry Blueskin Tape

Link - http://henry.com/airandvapor/nonpermeable/blueskinWB

Typar Tape

Link - http://typar.com/homeowner/products/accessories/

Tuck Tape

Link - http://www.cttgroup.com/cantech/en/details/135/ 


\section{References}

Building Science Digest - 013: Rain Control in Buildings, Building Science Corporation, 2006, www.buildingscience.com, accessed July 2012

Building Science Digest - 105: Understanding Drainage Planes, Building Science Corporation, 2006, www.buildingscience.com, accessed July 2012

Building Science Digest - 144: Increasing the Durability of Building Constructions, Building Science Corporation, 2006, www.buildingscience.com, accessed July 2012

Building Science Corporation. (2007) "Water Management Details for Residential Buildings." Building Science Corporation, www.buildingscience.com, accessed July 2012

Building Science Guides and Manuals: Water Management Details for Residential Buildings Housewraps/Flashings/Windows, Building Science Corporation, 2007, www.buildingscience.com, accessed July 2012

Building Science Information Sheet - 303: Common Flashing Details, Building Science Corporation, 2009, www.buildingscience.com, accessed July 2012

ICBO Evaluation Service, Inc. (2001) “Acceptance Criteria for Flashing Materials” AC148, Whittier, CA.

ICC Evaluation Service, Inc. (2003) "Interim Criteria for Foam Plastic Sheathing Panels Used As Weather-Resistive Barriers" AC71, Whittier, CA.

Lstiburek, J.W. (January 2010). "Building Sciences: Mind the Gap, Eh?.” ASHRAE Journal (vol. 52); pp. 57-63.

Lstiburek, J. (2006) Water Management Guide. Building Science Press: Westford, MA. 


\section{Appendix A: Homebuilder Interviews}

Six homebuilders were interviewed who represent the experience of building more than 27,000 homes in 2011. Builders were asked the following questions and BSC facilitated the discussions that followed. The findings were the basis for the Best Practices and Construction Details sections within the measure guideline.

- Do you use taped insulating sheathing as the drainage plane?

- Do you build your walls with two drainage planes or one?

- What materials have you used as your drainage planes?

- How long have you been using taped drainage planes?

- Have you had callbacks related to failures? If yes, what did you find? If no, have you ever removed siding to see if it is still sticking?

- How come you have never used taped sheathing?

- Do you want to learn how to use taped insulating sheathing?

- Have you ever had issues with tape sticking to sheathing?

- What do you do to make tape stick to insulating sheathing?

- What tapes do you use?

- Have you ever switched manufacturers?

- Is there a manufacturer that you prefer?

- Do you always pair the insulating sheathing with the tape made for that sheathing?

- What insulating sheathing manufacturers do you use?

- Have you ever used self-adhered self-sealing membrane materials?

- Do you use termination mastics or tapes?

- What widths of tapes have you tried?

- Have you ever tried flashing the joints of the insulating sheathing?

- Do you integrate subsill flashings for all openings? 


\section{Appendix B: Future Research-Exposure Rack Recommendation Verification}

The purpose of constructing the exposure rack is to determine the best performing tapes and tape systems under harsh conditions while implementing some of the best practices and materials as recommended by the interviewed homebuilders. The theory would be that the best performing tape or system on the exposure rack would not perform any worse behind a protective cladding and would likely perform better.

\section{Exposure Rack Design}

The rack was tilted to 75 degrees from horizontal versus the normal 90 degrees to horizontal that a wall would stand. This lean increases incidental rain and night sky radiation based cooling, thereby increasing the severity of the weather conditions experienced by the tapes and systems. An overhang is not provided to help ensure all of the samples experience similar wetting. Gaps are left between the samples to help ensure the lower samples do not see the run-off from the upper samples. The panels are raised off the platform by 24 in. to limit the splash-back on the lower samples. The rack system is to be faced South for maximum solar exposure (both thermal cycling and degradation), but it is built on a mobile platform so that other orientations can be tested if desired. The test rack has been located in a zone 5 climate in an exposed location away from shading.

Three 4-ft $\times 8$-ft panels were built on 10 -ft tall racks and tilted back to 75 degrees from horizontal. The west panel has eight horizontal joint samples while the center and east panels have 20 panels each for a total of 48 tested joints. The west panel tests have an 11-in. $\times 22$-in. upper and lower section of insulation joined at the middle by a tape (Figure 16). The center and east panels have a 9-in. $\times 11$-in. upper and lower section of insulation joined at the middle by a tape (Figure 17). All panels have 6-in. on center cap-nail fasteners at the perimeter where the tape is applied as required by the insulation manufacturer. The tape is not shown in the drawings as the tape width, color, and translucence vary by manufacturer. The intention of having two different sized panels is to allow the tape to experience two different expansion and contraction tests. The panel layouts are shown in Figure 18 and Figure 19. The tapes that were installed to be tested and monitored are listed in Table 2. The tapes include acrylic, asphalt, and butyl adhesives and a range of facer materials and widths. Some tapes were installed and tested in combination. 


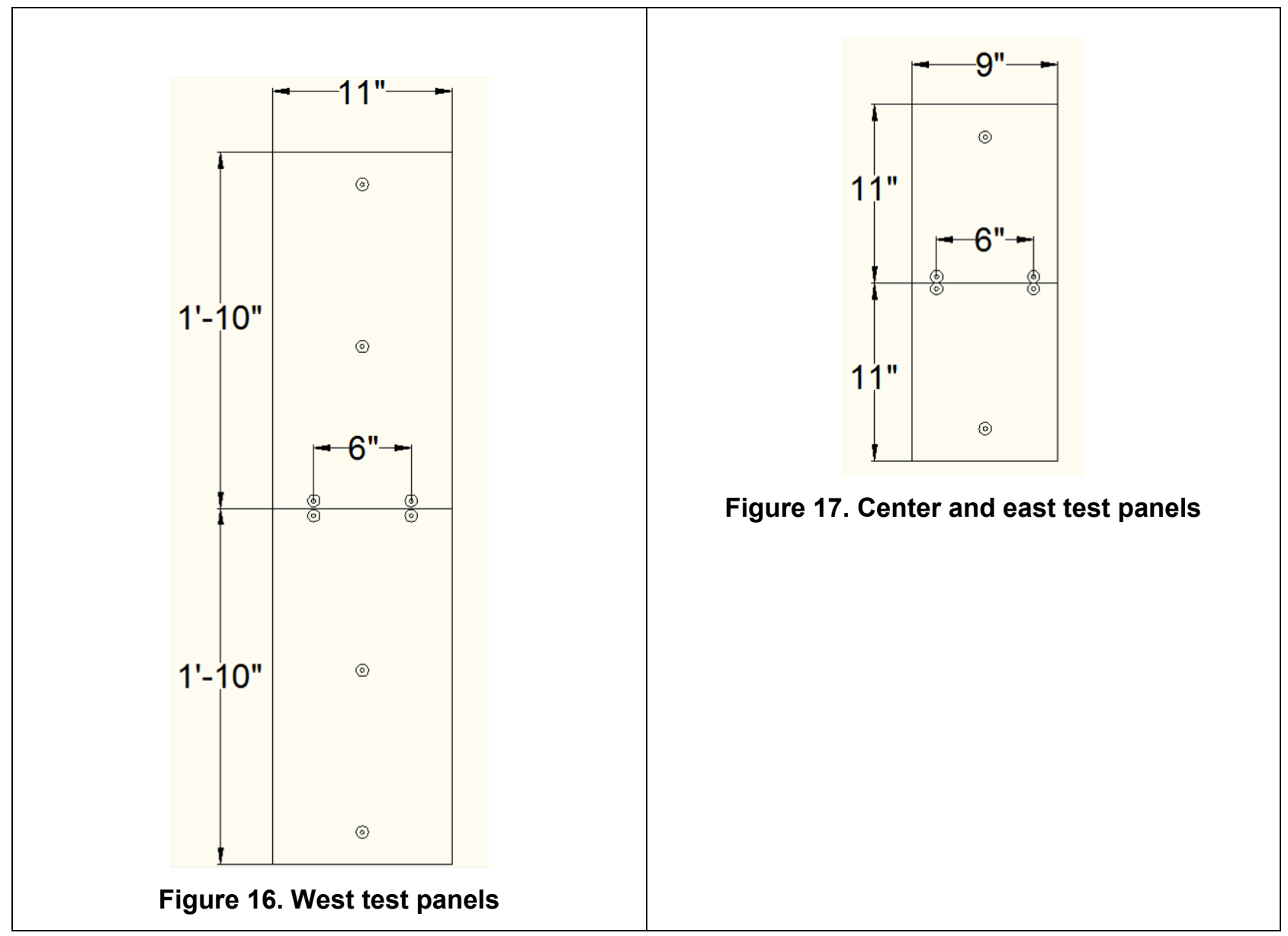




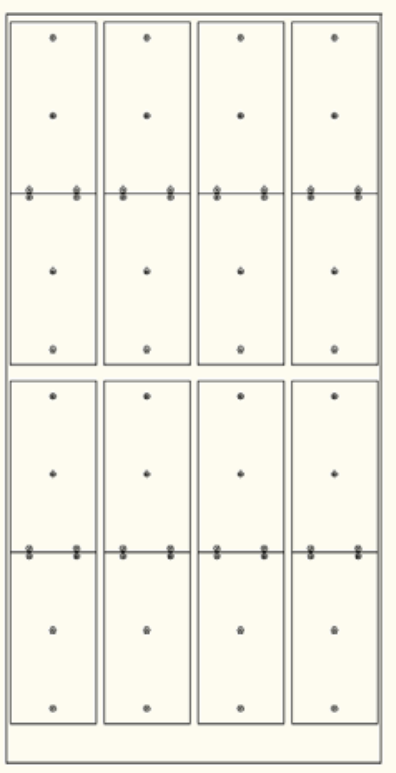

Figure 18. West test panel layout

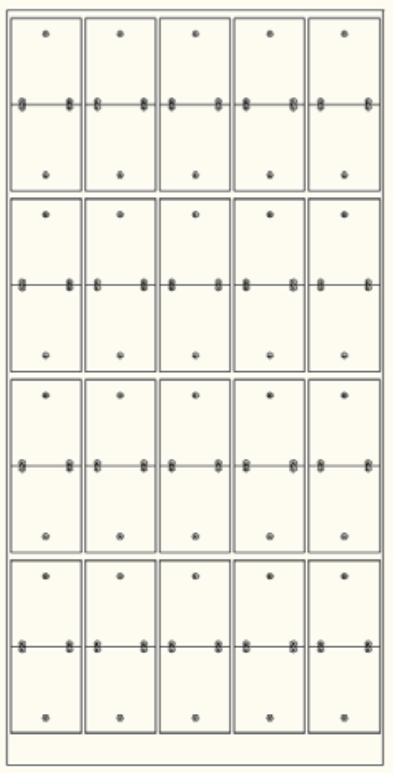

Figure 19. Center and east panel layout 


\section{Exposure Rack Testing}

The following photos show the exposure rack built as the follow-up experiment to the contractor's recommendations. Key items monitored over the long-term testing period will be visible changes in the surface characteristics, inspection for peeling or curling, lack of long-term adherence, and differences between tape material performance on XPS or ffPIC substrates. XPS and ffPIC insulation were considered because they can be used as a drainage plane. As this is a long-term test, no results are available at this time. These figures (Figure 20 through Figure 50) show the tapes within 7 days of installation. All tapes were installed on clean, warm, dry, dustfree surfaces at approximately $75^{\circ} \mathrm{F}$. Each tape was pressed into the surface by hand as recommended by the homebuilders.

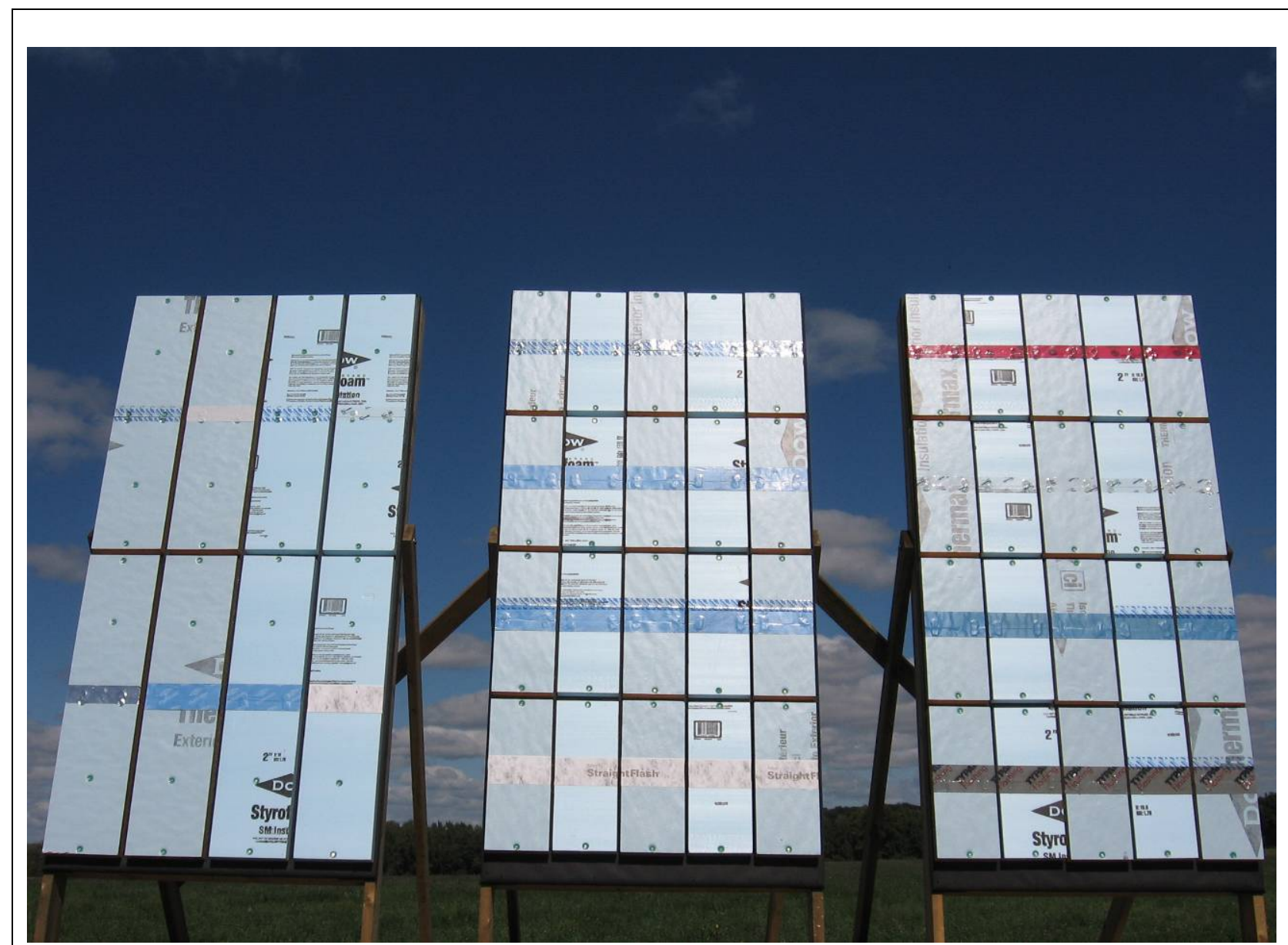

Figure 20. Full exposure test platform 


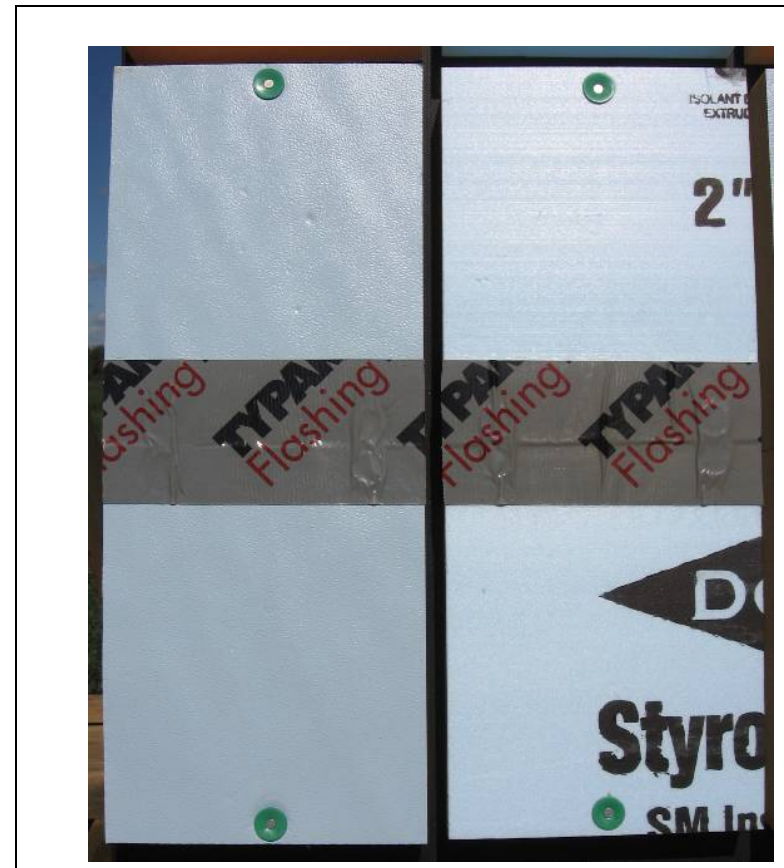

Figure 21. Typar tape on ffPIC (left) and XPS (right)

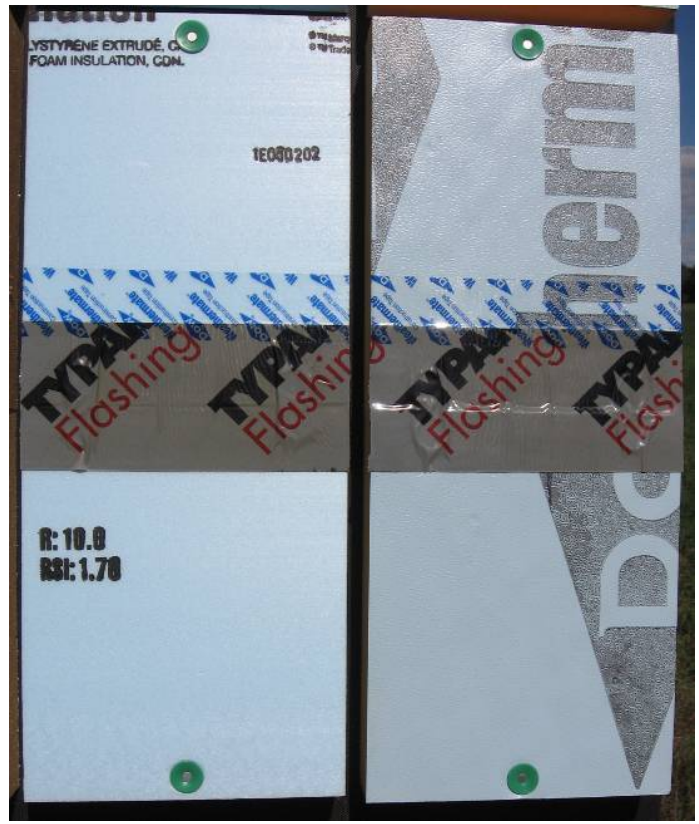

Figure 22. Typar tape with termination tape on ffPIC (right) and XPS (left)

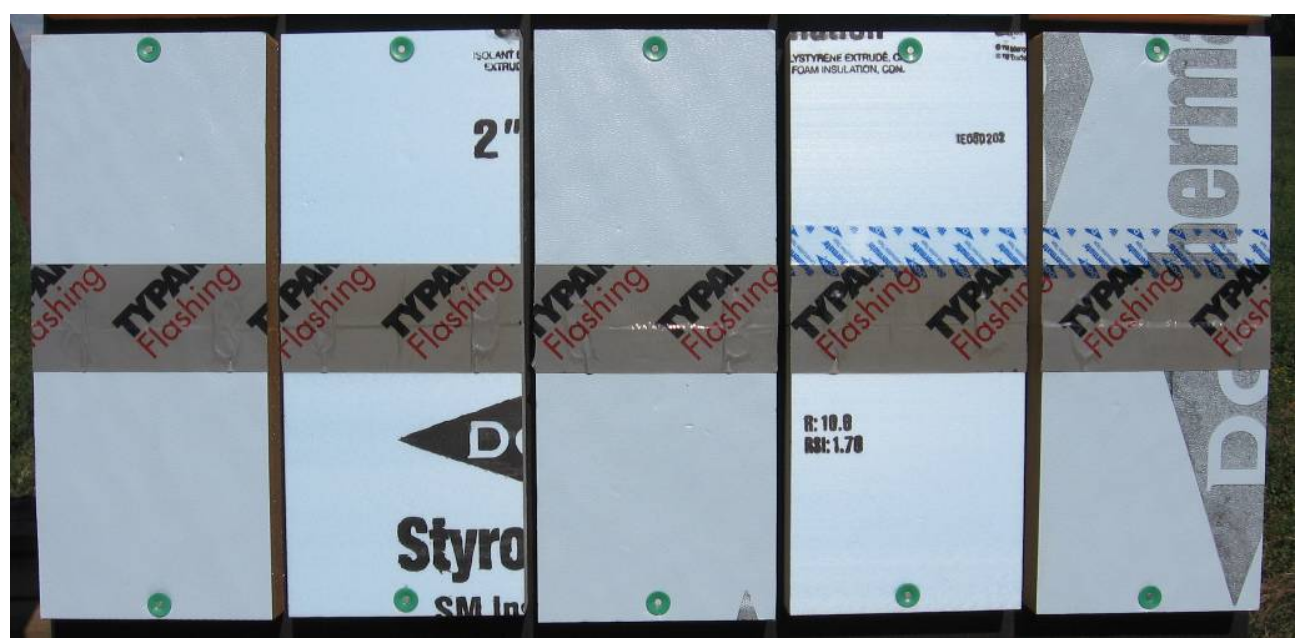

Figure 23. Typar rests 


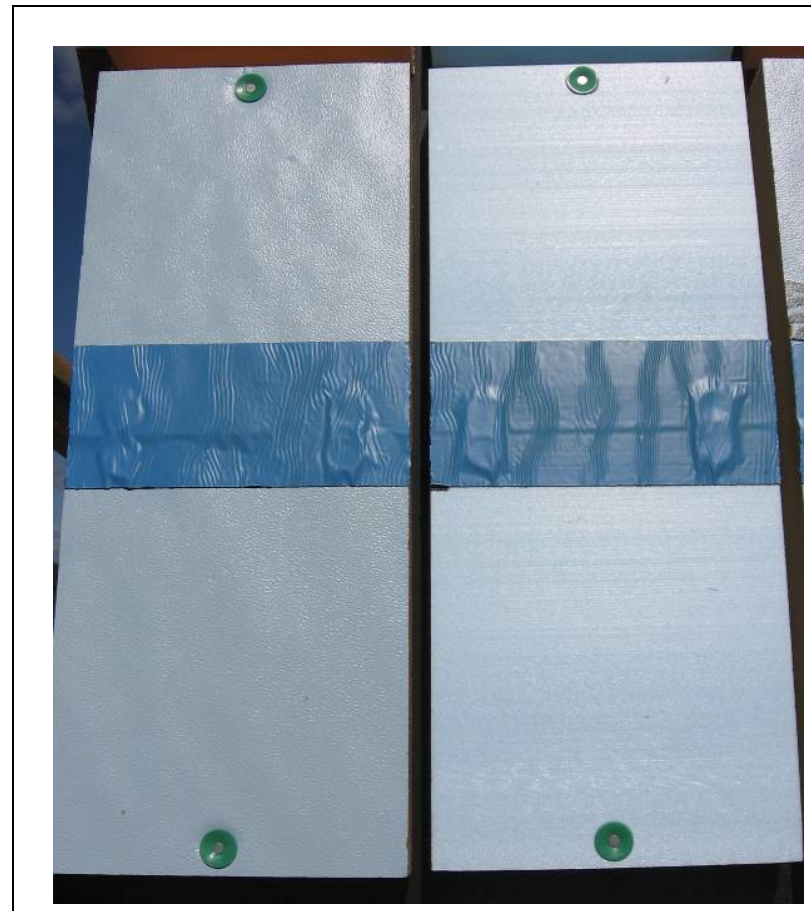

Figure 24. Henry Blueskin on ffPIC (left) and XPS (right)

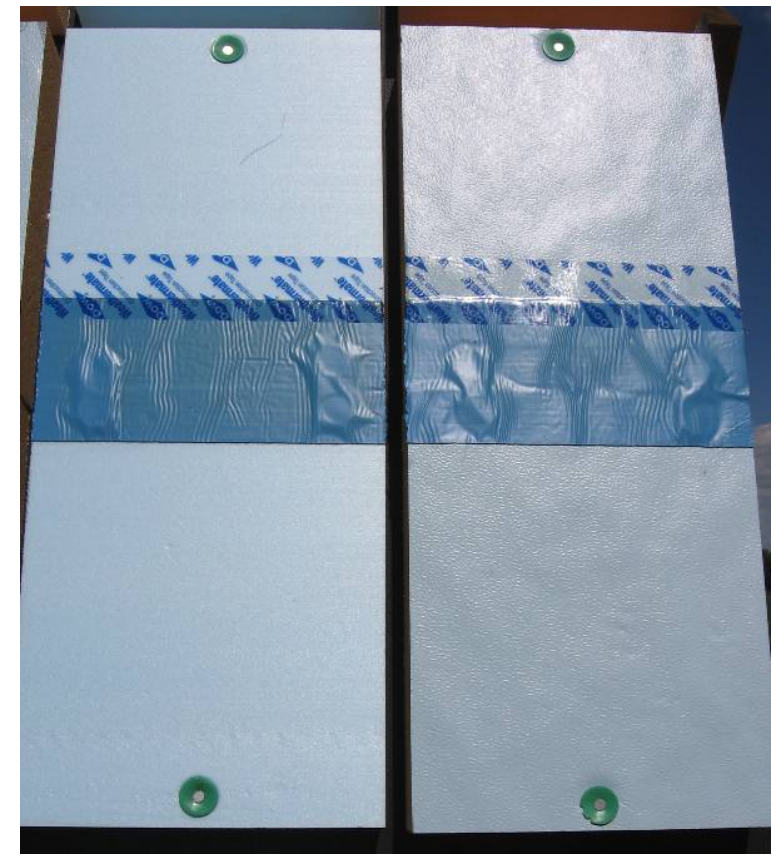

Figure 25. Henry Blueskin with termination tape on ffPIC (right) and XPS (left)

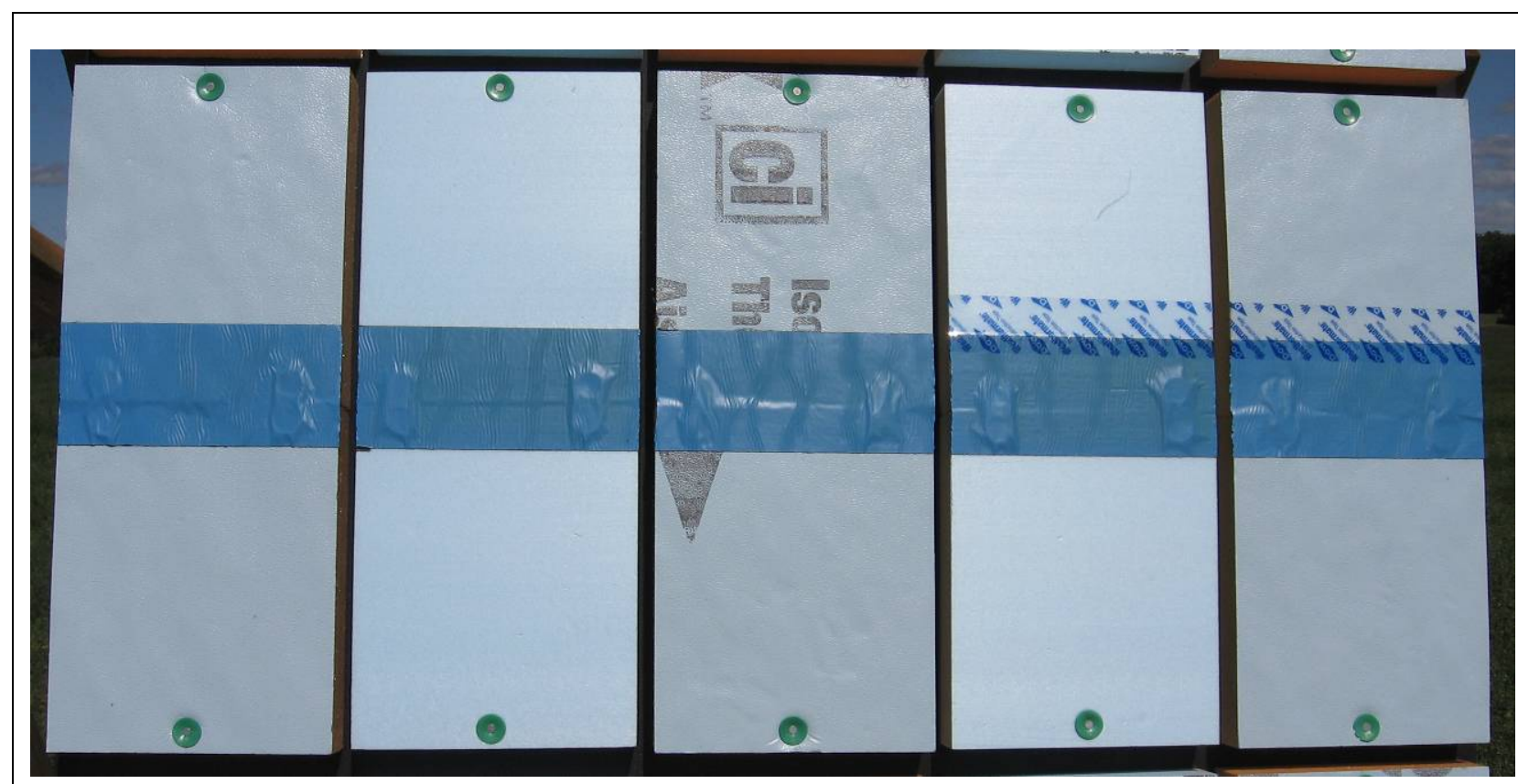

Figure 26. Henry Blueskin tests 


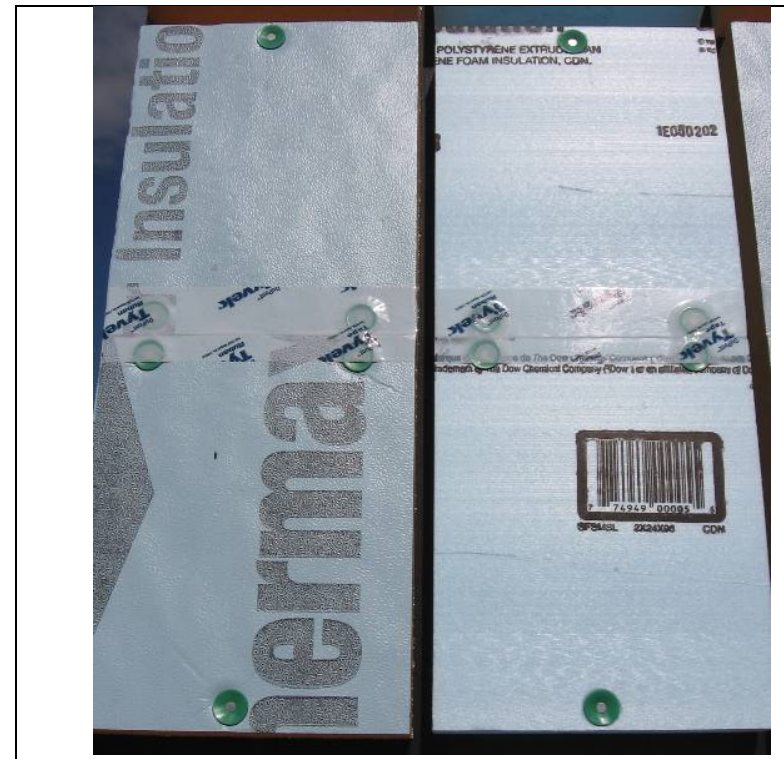

Figure 27. DuPont Tyvek tape on ffPIC (left) and XPS (right)

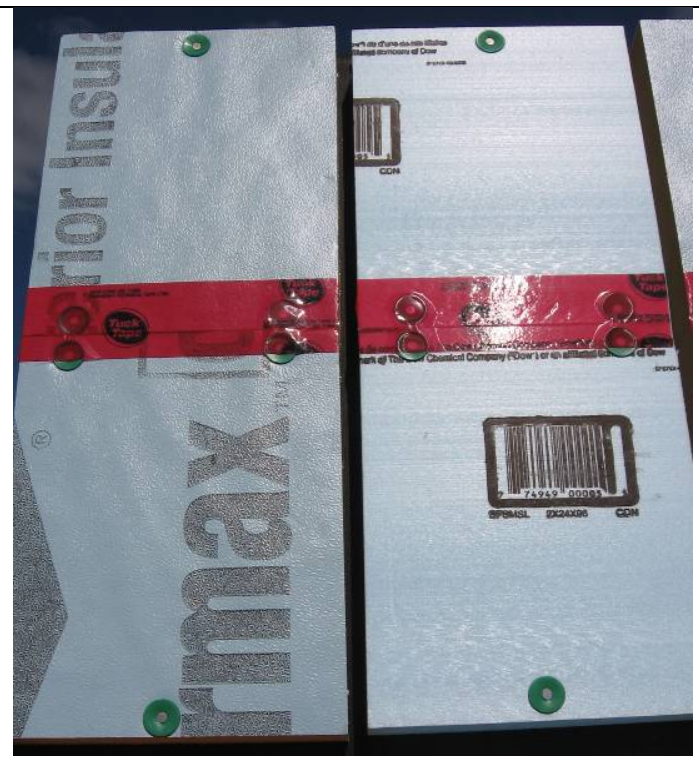

Figure 28. Tuck tape on ffPIC (left) and XPS (right)

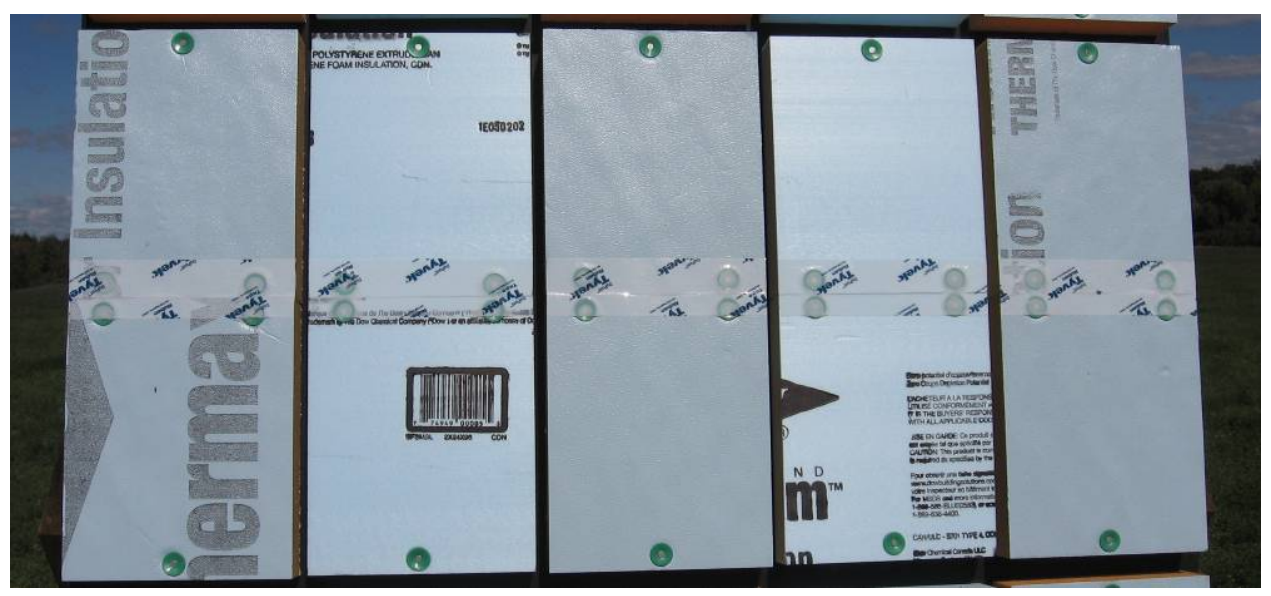

Figure 29. DuPont Tyvek tape tests

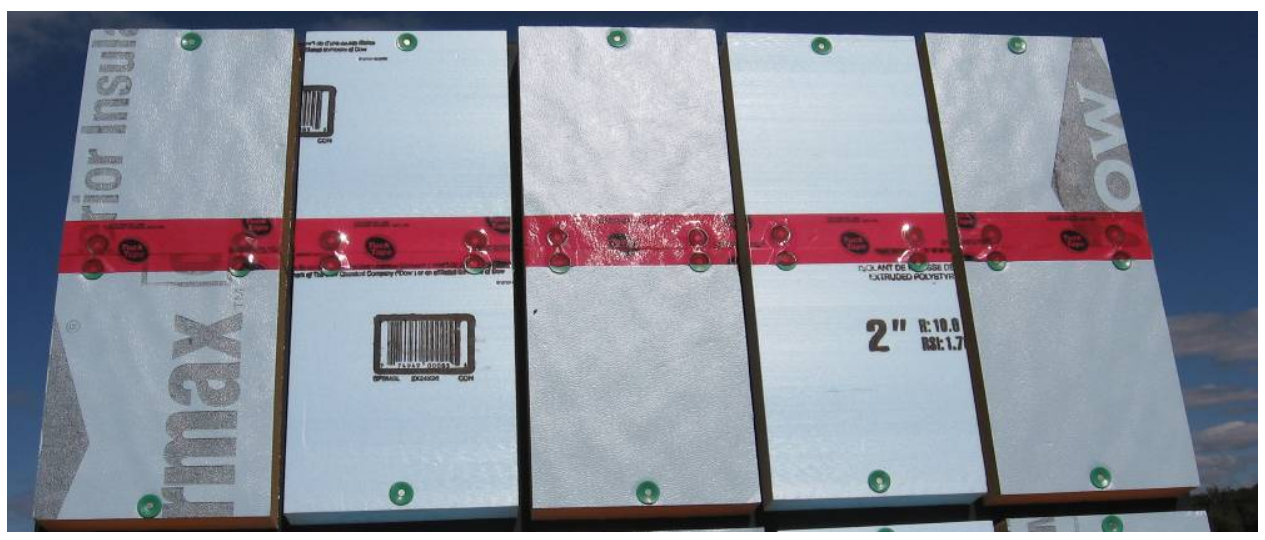

Figure 30. Tuck tape tests 


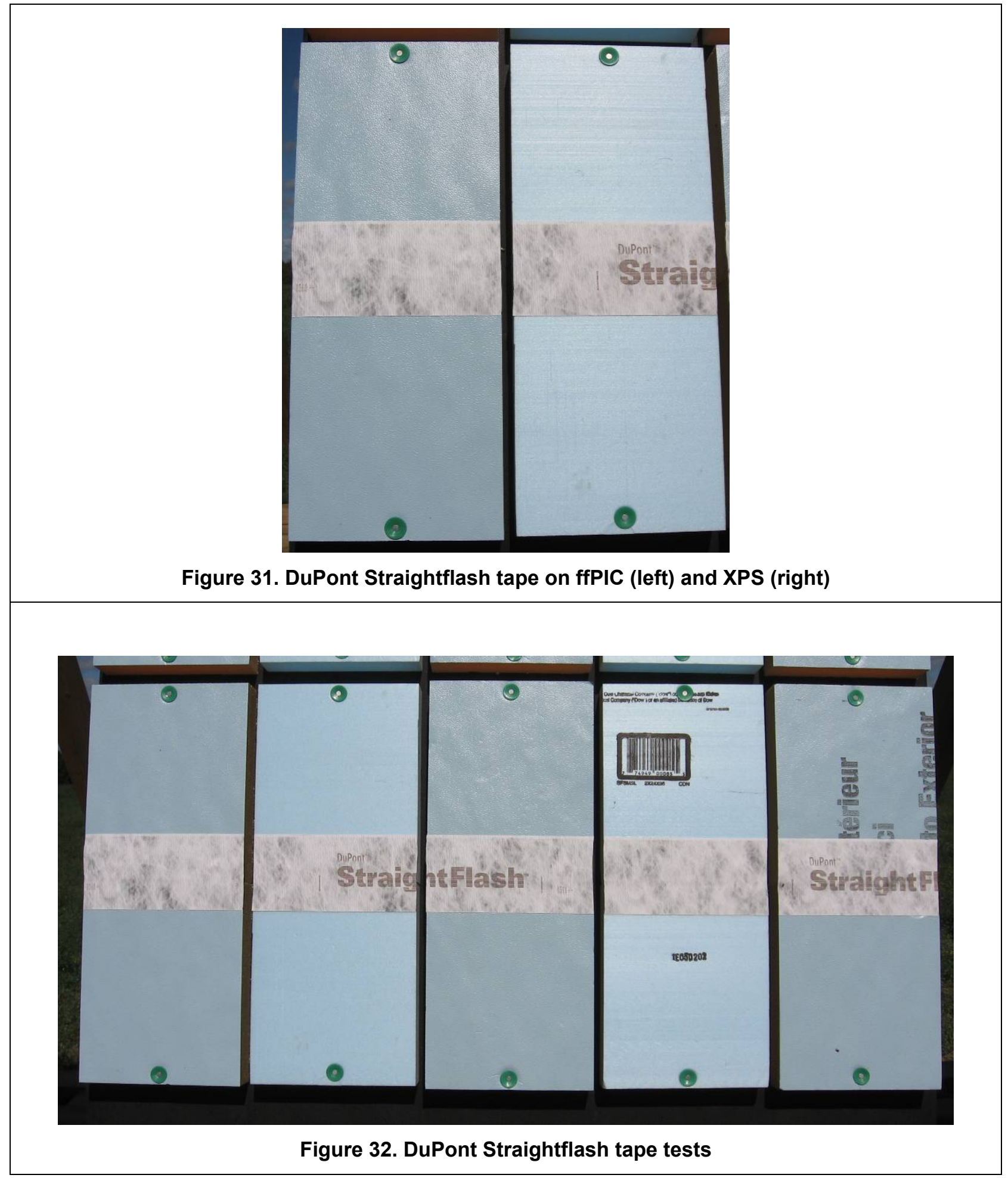




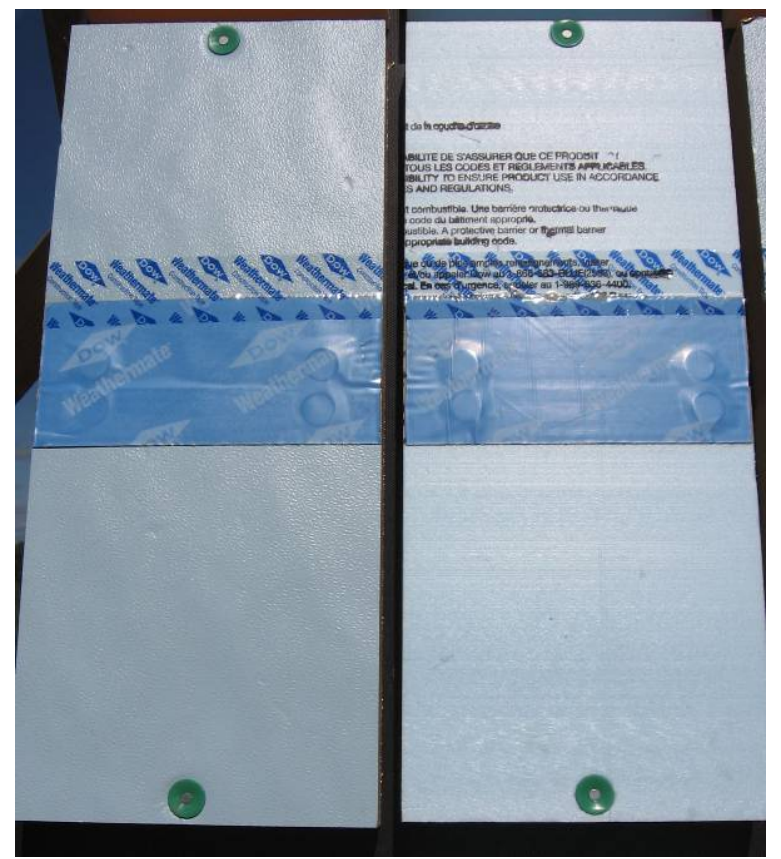

Figure 33. Dow Weathermate butyl with termination tape on ffPIC (left) and XPS (right)

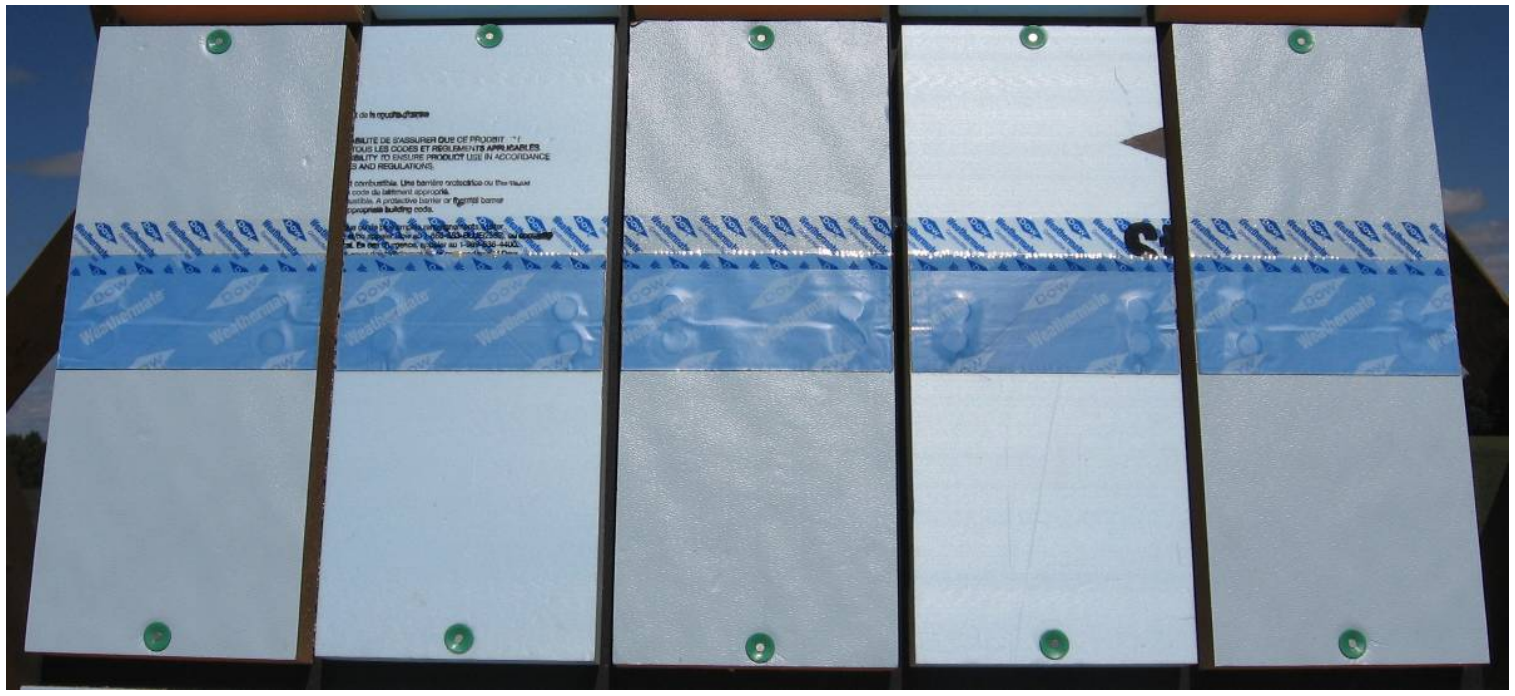

Figure 34. Dow Weathermate butyl with termination tape tests 


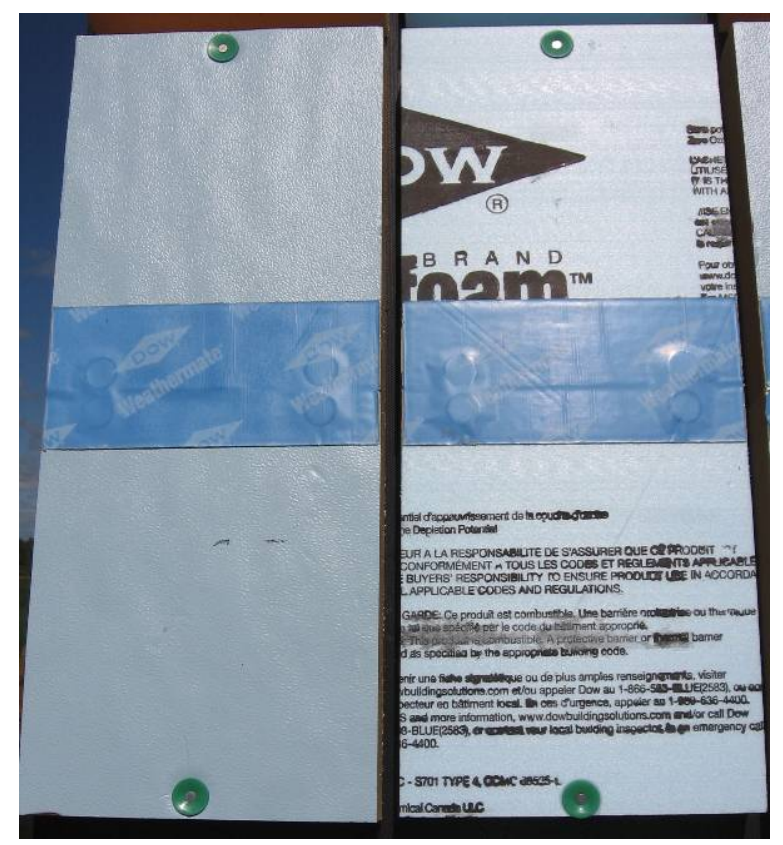

Figure 35. Dow Weathermate butyl on ffPIC (left) and XPS (right)

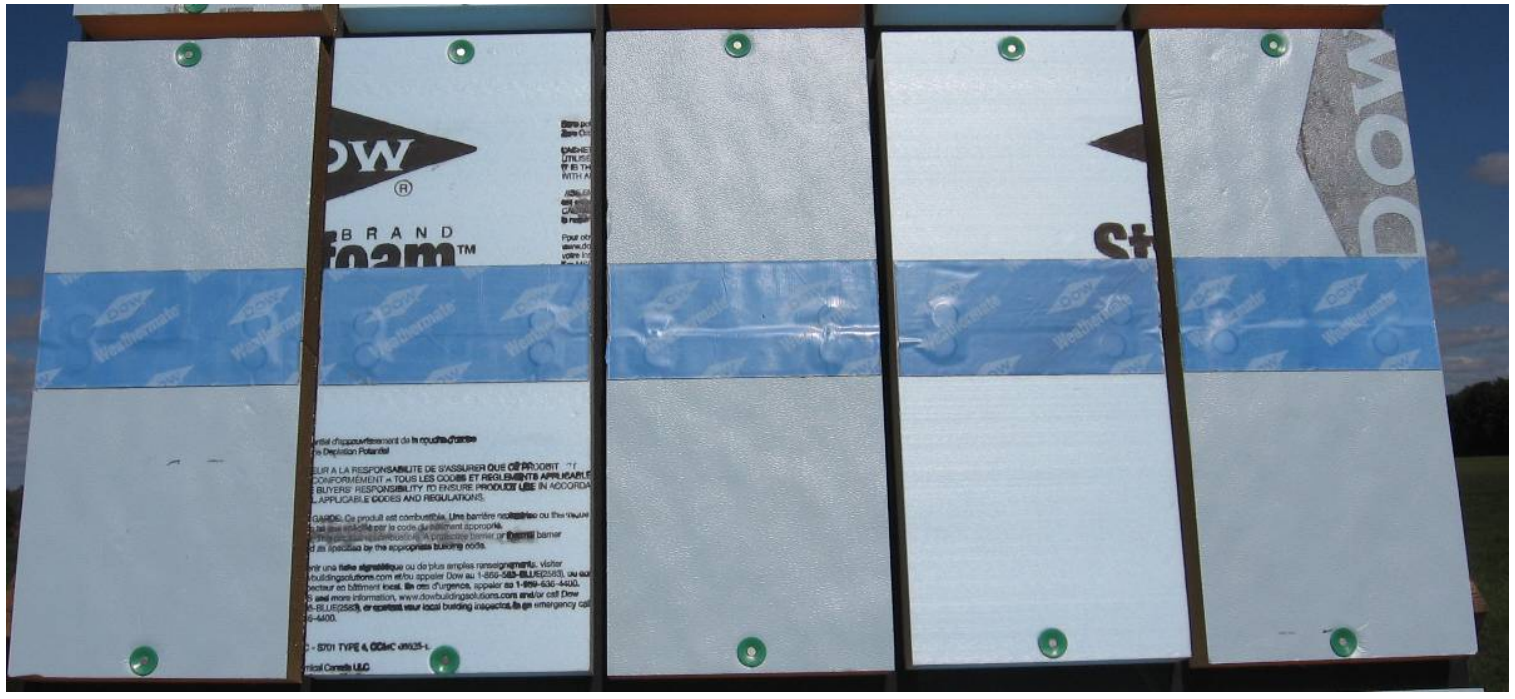

Figure 36. Dow Weathermate butyl tests 


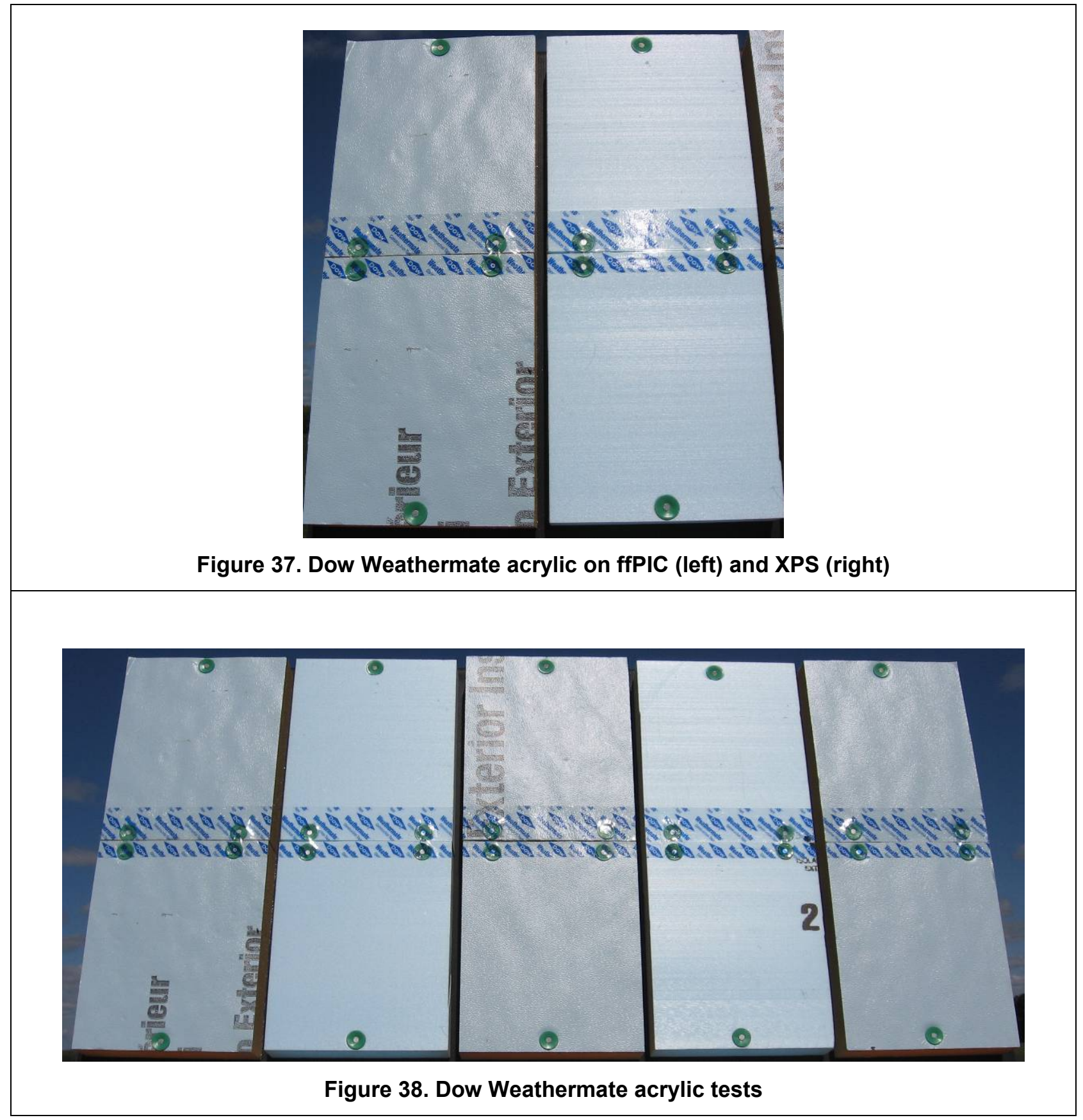




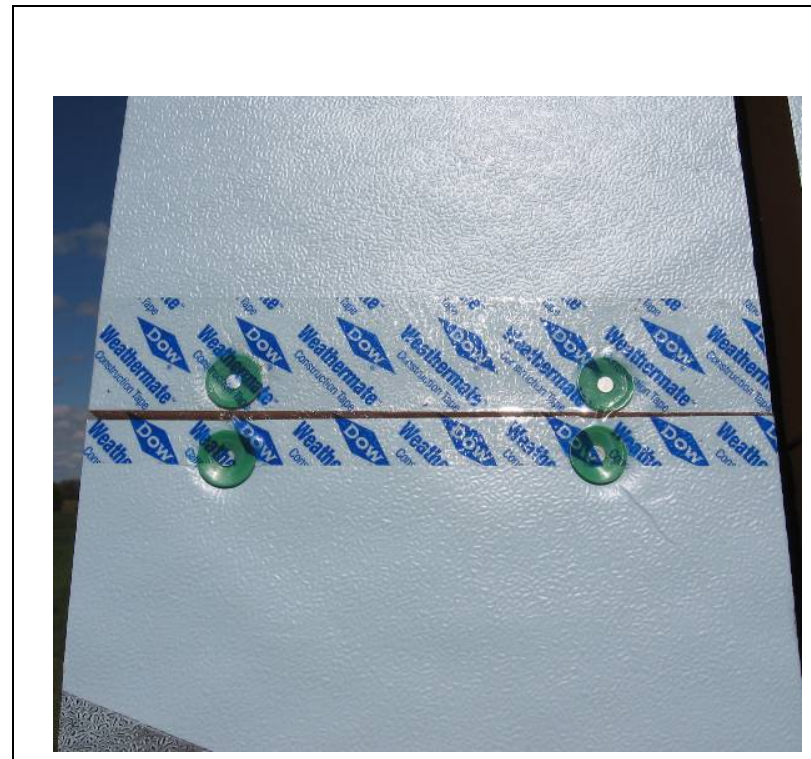

Figure 39. Dow Weathermate acrylic on ffPIClarge test

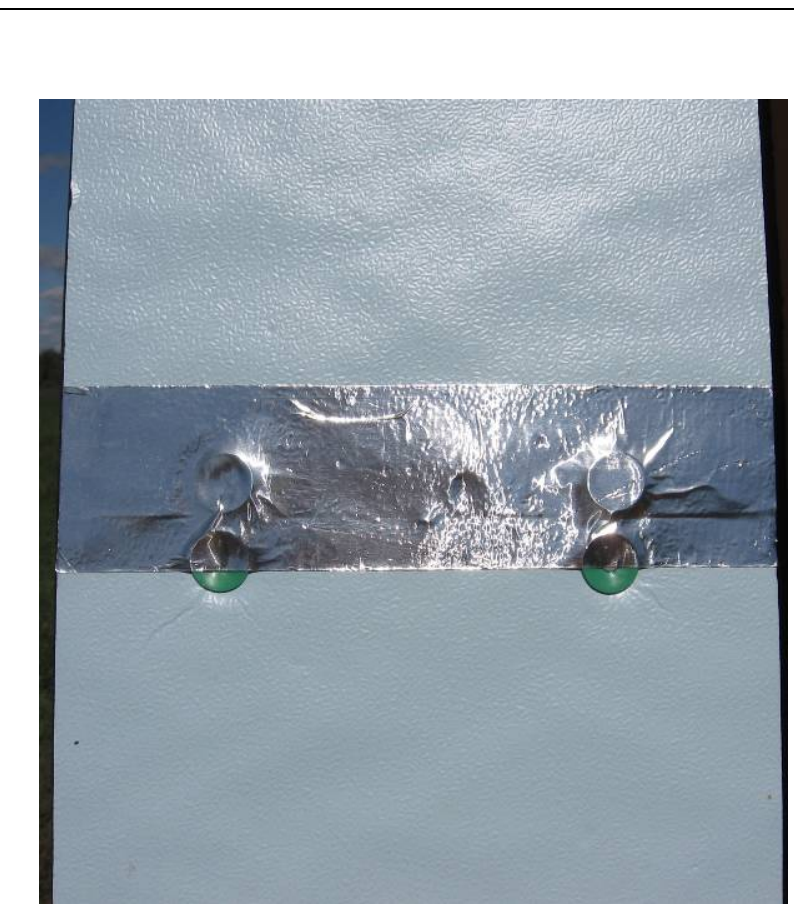

Figure 41. Dow aluminum foil on ffPIClarge test

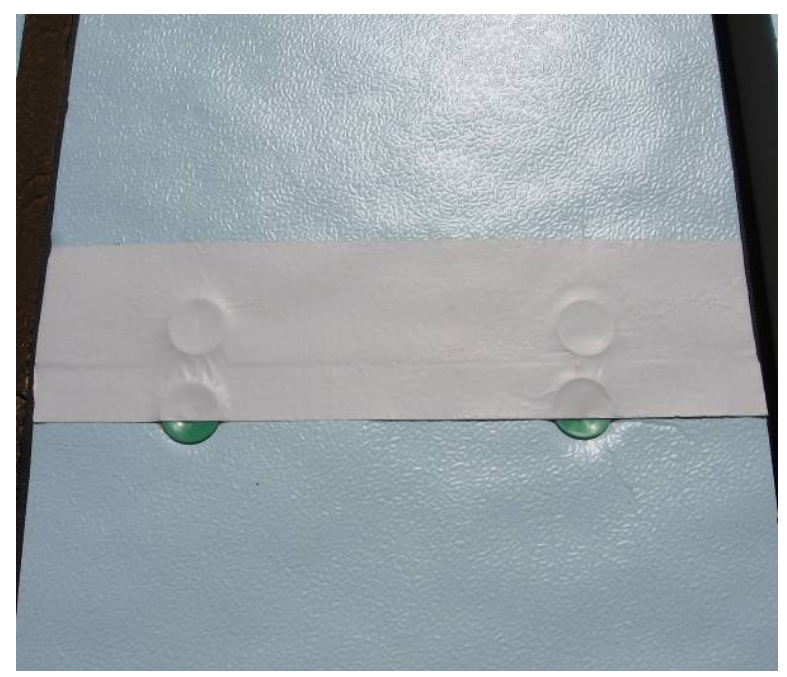

Figure 40. Dow aluminum white foil on ffPIClarge test

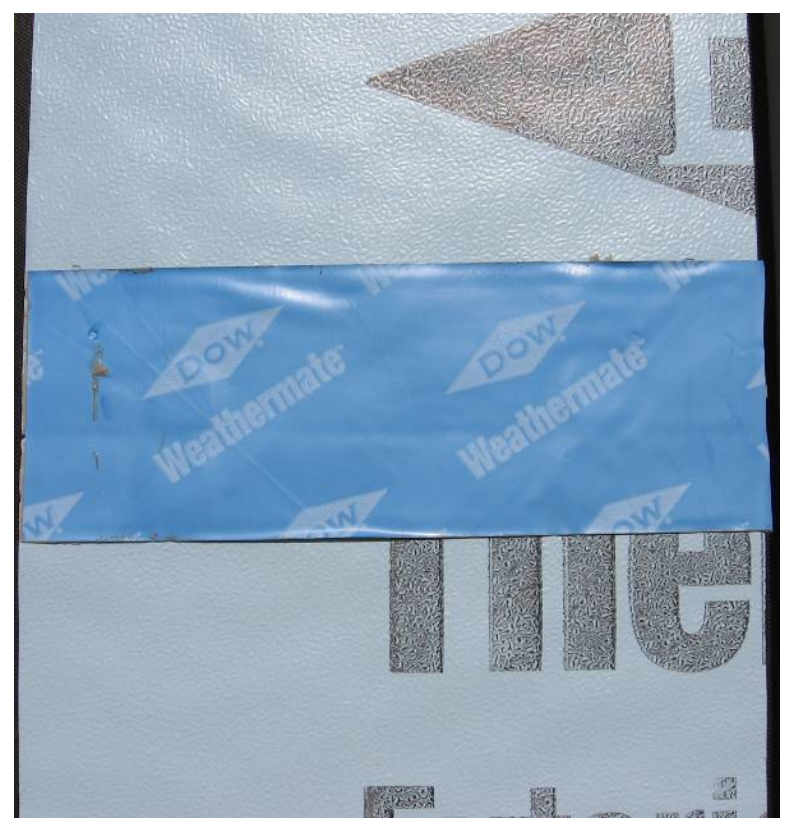

Figure 42. Dow Weathermate butyl on ffPIClarge test 


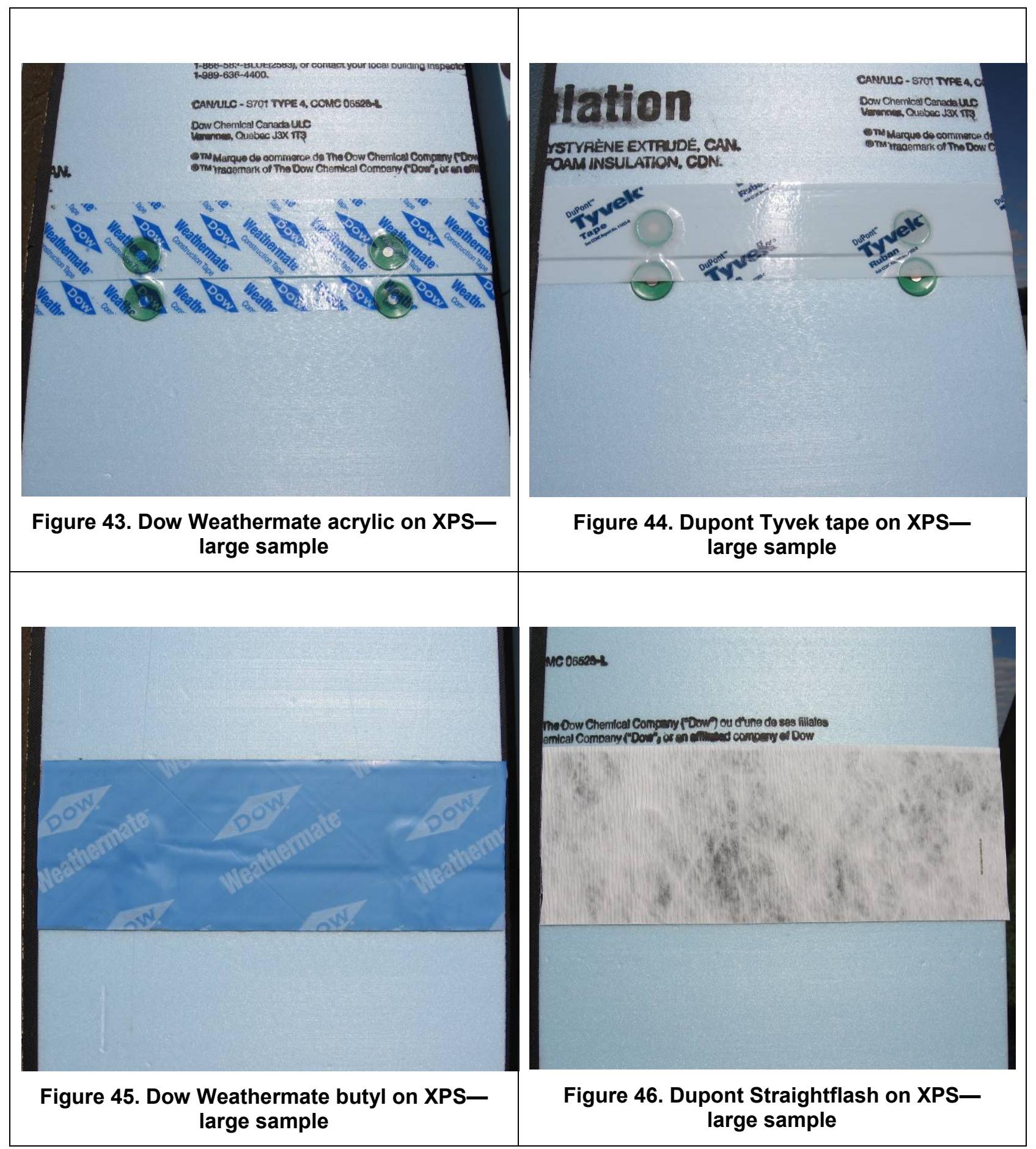




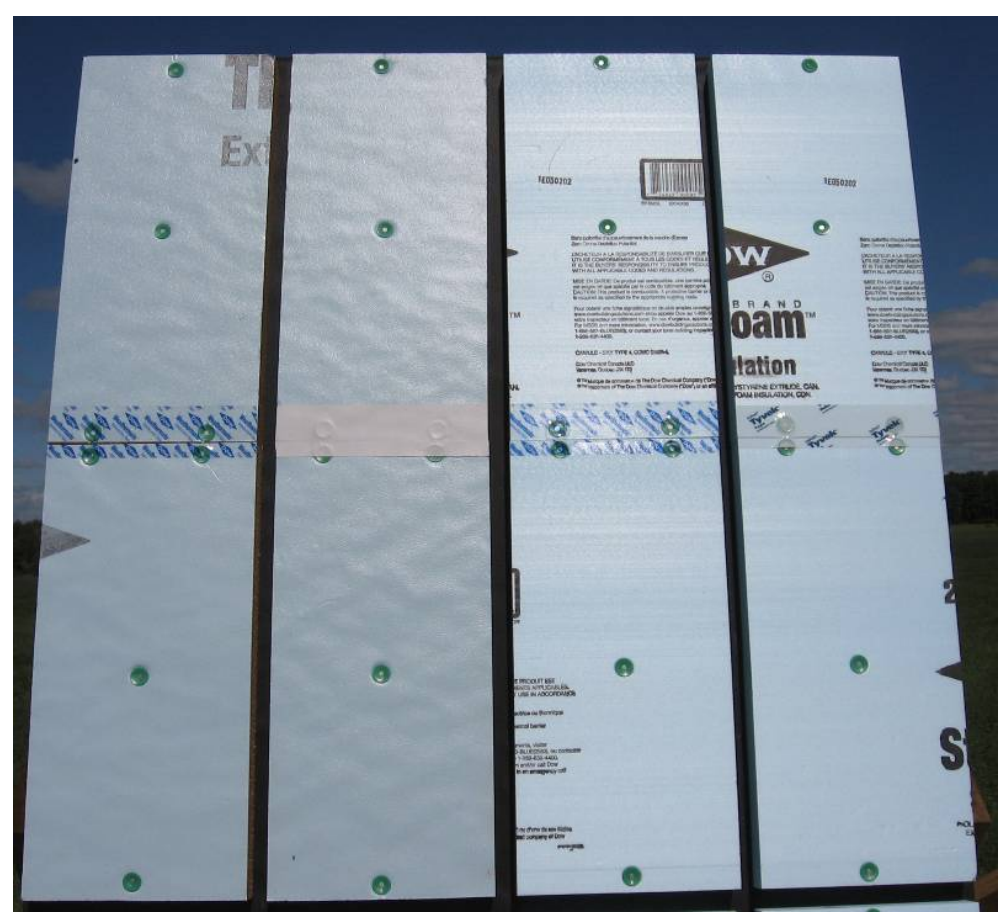

Figure 47. West large sample tests upper

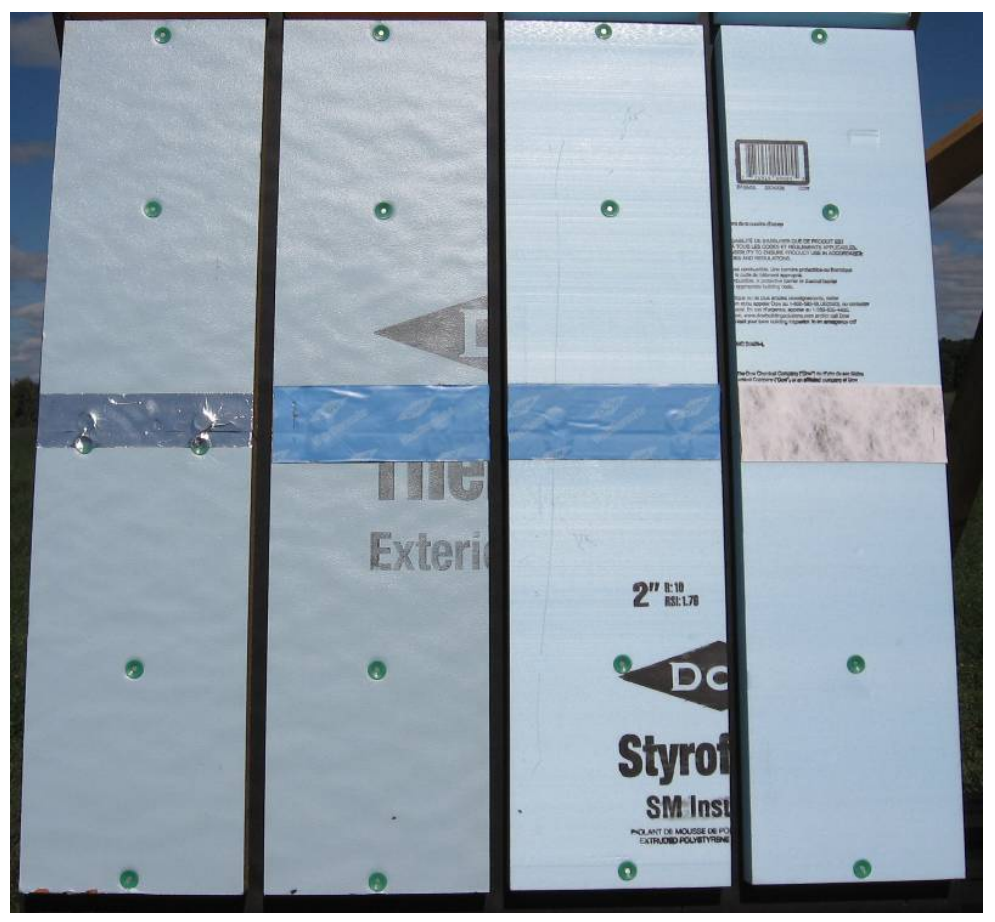

Figure 48. West large sample tests lower 


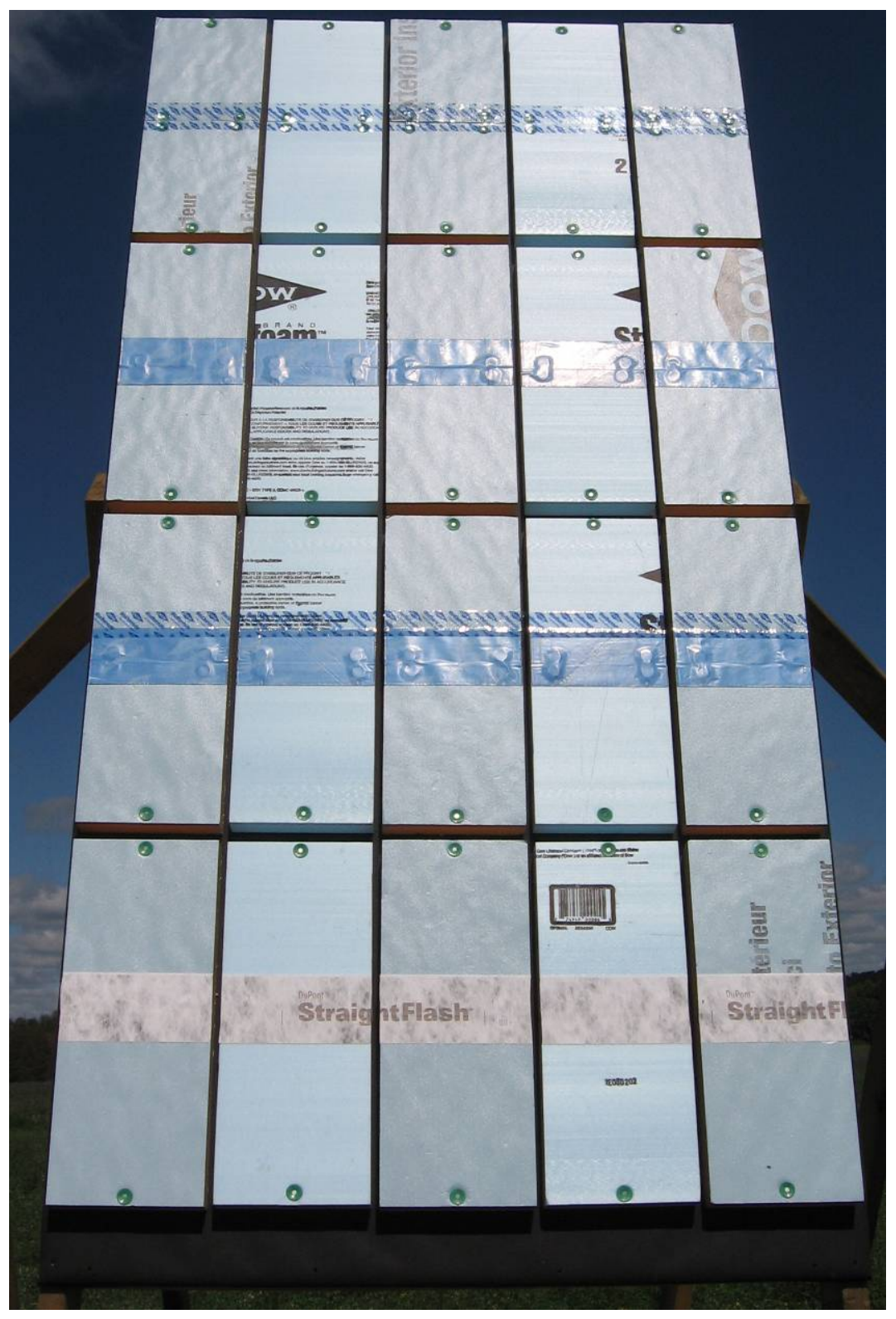

Figure 49. Center small sample tests 


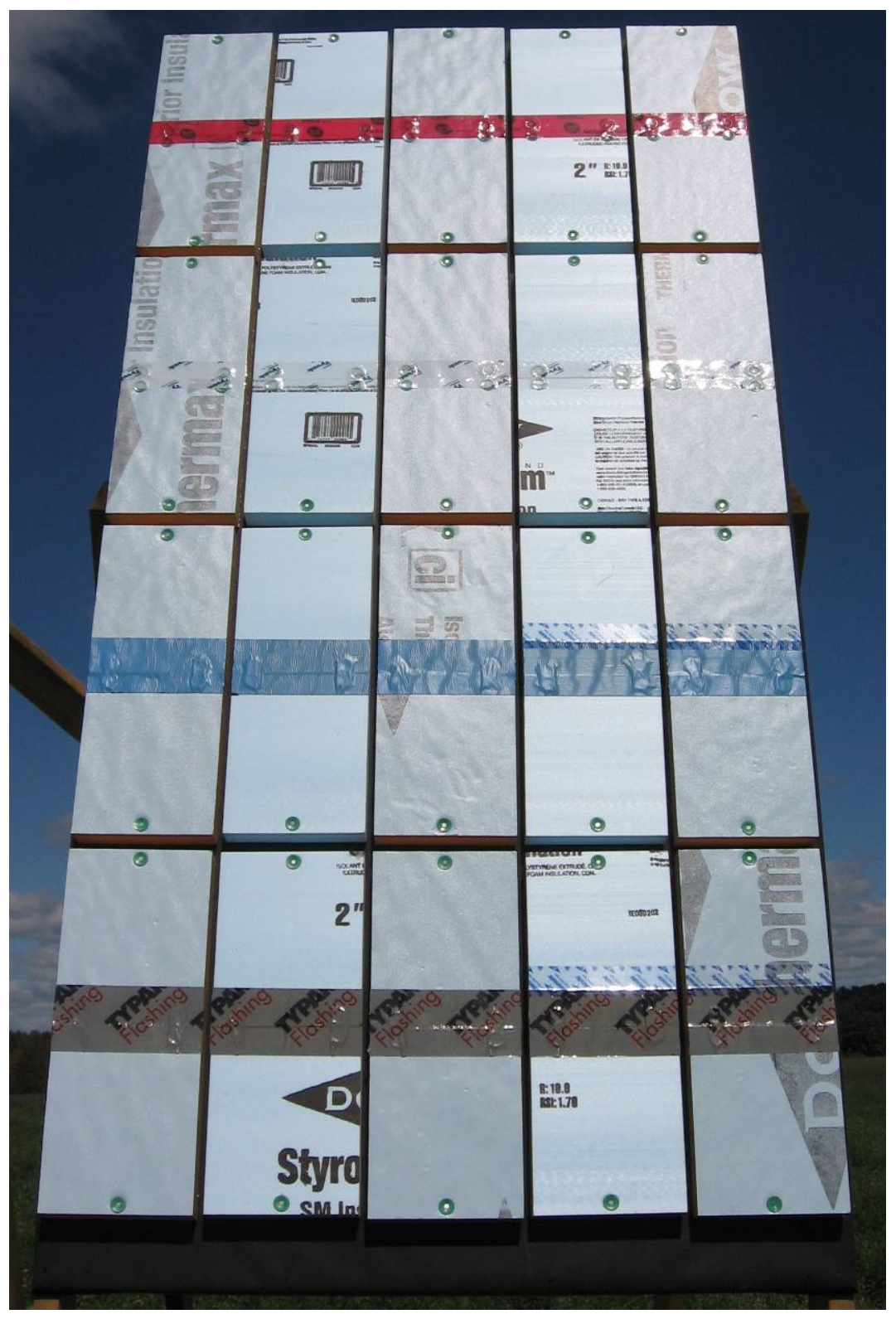

Figure 50. East small sample tests 
